\title{
Role of Lipid Accumulation and Inflammation in Atherosclerosis: Focus on Molecular and Cellular Mechanisms
}

OPEN ACCESS

Edited by:

Michael Bukrinsky,

George Washington University,

United States

Reviewed by:

Chieko Mineo,

University of Texas Southwestern Medical Center, United States

Daisy Sahoo,

Medical College of Wisconsin,

United States

*Correspondence:

Evgeny E. Bezsonov

evgeny.bezsonov@gmail.com

Mahmoud Rafieian-Kopaei

rafieian@yahoo.com

Specialty section:

This article was submitted to

Atherosclerosis and Vascular

Medicine,

a section of the journal

Frontiers in Cardiovascular Medicine

Received: 10 May 2021

Accepted: 20 July 2021

Published: 06 September 2021

Citation:

Malekmohammad K, Bezsonov EE and Rafieian-Kopaei M (2021) Role of Lipid Accumulation and Inflammation

in Atherosclerosis: Focus on Molecular and Cellular Mechanisms. Front. Cardiovasc. Med. 8:707529,

doi: 10.3389/fcvm.2021.707529

\begin{abstract}
Khojasteh Malekmohammad ${ }^{1}$, Evgeny E. Bezsonov ${ }^{2,3,45 *}$ and Mahmoud Rafieian-Kopaei ${ }^{6 *}$
${ }^{1}$ Department of Biology, College of Sciences, Shiraz University, Shiraz, Iran, ${ }^{2}$ Laboratory of Angiopathology, Institute of General Pathology and Pathophysiology, Moscow, Russia, ${ }^{3}$ Laboratory of Cellular and Molecular Pathology of Cardiovascular System, Institute of Human Morphology, Moscow, Russia, ${ }^{4}$ Institute for Atherosclerosis Research, Moscow, Russia, ${ }^{5}$ Department of Biology and General Genetics, I.M. Sechenov First Moscow State Medical University (Sechenov University), Moscow, Russia, ${ }^{6}$ Medical Plants Research Center, Basic Health Sciences Institute, Shahrekord University of Medical Sciences, Shahrekord, Iran
\end{abstract}

Atherosclerosis is a chronic lipid-driven and maladaptive inflammatory disease of arterial intima. It is characterized by the dysfunction of lipid homeostasis and signaling pathways that control the inflammation. This article reviews the role of inflammation and lipid accumulation, especially low-density lipoprotein (LDL), in the pathogenesis of atherosclerosis, with more emphasis on cellular mechanisms. Furthermore, this review will briefly highlight the role of medicinal plants, long non-coding RNA (IncRNA), and microRNAs in the pathophysiology, treatment, and prevention of atherosclerosis. Lipid homeostasis at various levels, including receptor-mediated uptake, synthesis, storage, metabolism, efflux, and its impairments are important for the development of atherosclerosis. The major source of cholesterol and lipid accumulation in the arterial wall is proatherogenic modified low-density lipoprotein (mLDL). Modified lipoproteins, such as oxidized low-density lipoprotein (ox-LDL) and LDL binding with proteoglycans of the extracellular matrix in the intima of blood vessels, cause aggregation of lipoprotein particles, endothelial damage, leukocyte recruitment, foam cell formation, and inflammation. Inflammation is the key contributor to atherosclerosis and participates in all phases of atherosclerosis. Also, several studies have shown that microRNAs and IncRNAs have appeared as key regulators of several physiological and pathophysiological processes in atherosclerosis, including regulation of HDL biogenesis, cholesterol efflux, lipid metabolism, regulating of smooth muscle proliferation, and controlling of inflammation. Thus, both lipid homeostasis and the inflammatory immune response are closely linked, and their cellular and molecular pathways interact with each other.

Keywords: atherosclerosis, LDL, cholesterol, inflammation, IncRNA, microRNA, medicinal plants

\section{INTRODUCTION}

Atherosclerosis is an important cause of cardiovascular diseases such as ischemic heart disease and stroke. This complex multifactorial disease has chronic and progressive pathology characterized by lipid accumulation, low-grade inflammation in the walls of large- and medium-sized arteries, and endothelial dysfunction $(1,2)$. 
Two key factors in the pathogenesis of atherosclerosis are cholesterol deposition and chronic inflammation (3). Atherosclerosis has three significant stages including fatty streak formation, induction of atheroma, and atherosclerotic plaques (4).

Reactive oxygen species (ROS) and reactive nitrogen species (RNS) damage the cellular function of lipids, proteins, and carbohydrates, and cause lipid peroxidation and low-density lipoprotein (LDL) oxidation (5). Oxidized LDL (ox-LDL) can remain in the vascular intima. ox-LDL has a crucial role in the initiation and development of atherosclerosis through inducing endothelial cell (EC) dysfunction, increasing leukocyte adhesiveness, inducing the expression of leukocyte and monocyte adhesion molecules on the endothelial surface such as Vascular Cell Adhesion Molecule-1 (VCAM), Intercellular Adhesion Molecule-1 (ICAM), E selectin and P-selectins (3, 6, 7). Monocytes, $\mathrm{T}$ lymphocytes, and mast cells are taken up into vascular wall intima by these adhesion molecules. $T$ cells can respond to inflammatory signals by producing $\gamma$-interferon $(\mathrm{IFN}-\gamma)$ and lymphotoxin, and tumor necrosis factor $\beta$ (TNF$\beta)(8,9)$. Monocytes are converted into macrophages in the sub-endothelial space through Monocyte Chemotactic Protein1 (MCP-1), Macrophage Colony-Stimulating Factor (M-CSF), and Interleukin-8 (IL-8). Macrophages uptake ox-LDL molecules via the scavenger receptor-A family to form lipid-laden foam cells. Yellow foam cells aggregate on the arterial walls and cause the development of fatty streaks $(10,11)$. A fibrous atherosclerotic plaque cap is formed from the fatty streak during the migration of Smooth Muscle Cells (SMCs) from media to intima and SMCs proliferation $(9,12)$. At advanced stages of atherosclerosis, Macrophages and $\mathrm{T}$ lymphocytes of fibrous atherosclerotic plaque cap secrete proteolytic enzymes such as metalloproteinase to reduce the stability of the fibrous cap and lyse the fibrous cap extracellular matrix. Breakdown of fibrous cap collagen content leads to coagulation process, blood clot

\footnotetext{
Abbreviations: ABCA1, ATP binding cassette transporter A1; ABCG1, ATPbinding cassette transporters G1; ApoB, apolipoprotein B; CIC, circulating immune complexes; CRP, C-Reactive Protein; EC, endothelial cell; EndMT, endothelial-to-mesenchymal transition; eNOS, endothelial nitric oxide synthase; HDL-C, high-density lipoprotein cholesterol; ICAM, Intercellular Adhesion Molecule-1; IDL, intermediate-density lipoproteins; IFN- $\gamma, \gamma$-interferon; IL-8, Interleukin-8; JNK, cJun NH2-terminal kinase; LDL, low-density lipoprotein; LDL-C, low-density lipoprotein cholesterol; IncRNA, long non-coding RNA; LOX-1, the lectin-like oxidized LDL 1 receptor; Lp-PLA2, lipoprotein-associated phospholipase A2; LPL, lipoprotein lipase; LPS, lipopolysaccharide; LRP1, lowdensity lipoprotein receptor-related protein 1; lysoPC, lysophosphatidylcholine; M-CSF, Macrophage Colony-Stimulating Factor; MALAT1, metastasis-associated lung adenocarcinoma transcript 1; MCP-1, Monocyte Chemotactic Protein1; mLDL, modified low-density lipoprotein; MMP, Matrix Metalloproteinase; NEAT1, nuclear enriched abundant transcript; NF-kB, nuclear transcription factor-kB; NFIA, Nuclear factor I A; ox-LDL, oxidized low-density lipoprotein; PAR, Protease Activated Receptor; RNS, reactive nitrogen species; ROS, Reactive oxygen species; S-SMase, sphingomyelinase; SMCs, Smooth Muscle Cells; SR, scavenger receptors; SR-BI, scavenger receptor class B type I; SR-E1, the lectinlike oxidized LDL 1 receptor; SRC, non-receptor tyrosine kinase; STAT3, signal transducer and activator of transcription 3; TC, total cholesterol; TG, triglyceride; TLR4, Toll-like receptor 4; TNF- $\beta$, tumor necrosis factor $\beta$; VCAM, Vascular Cell Adhesion Molecule-1; VLDL, very-low-density lipoproteins; VSMCs, vascular smooth muscle cells.
}

formation, thrombus formation, and blockade of the arteries $(3,13,14)$.

The pathophysiologic feature of atherosclerosis is an inflammatory, cellular, and metabolic process $(4,8)$. So, elucidating atherosclerosis pathogenesis is vital for understanding disease progression and the development of new therapeutics. This review will discuss the role and significance of inflammation and lipid accumulation especially LDL in the pathogenesis of atherosclerosis with more emphasis on cellular mechanisms. Furthermore, this review will highlight briefly the role of medicinal plants, long non-coding RNA, and microRNAs in the pathophysiology, treatment, and prevention of atherosclerosis.

\section{SOURCES OF THE INFORMATION}

The comprehensive information in this review article was obtained from noteworthy scientific databases, including Web of Science, PubMed, Science Direct, Scopus, and Google Scholar. The main search terms used in this study were atherosclerosis, LDL, IncRNA, microRNA, cholesterol, inflammation, and medicinal plants.

\section{RESULTS}

\section{Role of Lipid and Lipoprotein Accumulation in Atherosclerosis}

Various forms of lipoproteins and lipids are implicated in lipid trafficking such as chylomicrons, sphingolipids, ceramides, verylow-density lipoproteins (VLDL), cholesterol, apolipoproteins, including $\mathrm{ApoB}$ (apolipoprotein $\mathrm{B}$ ), intermediate-density lipoproteins (IDL), and low-density lipoprotein (LDL) (15-20). Lipid biomarkers are classic LDL and HDL, cholesterol, ox-LDL cholesterol, small dense LDL cholesterol, lipoprotein (a), and lipoprotein-associated phospholipase A2 (Lp-PLA2) (21).

Lipid homeostasis at various levels, including receptormediated uptake, synthesis, storage, metabolism, and efflux, as well as its impairment, are important for the development of atherosclerosis (22). Under normal physiological conditions, LDL in the cell can degrade in the lysosomes that prevent an imbalance of uptake, synthesis, efflux, and excessive lipid accumulation (23). The hypothesis of cholesterol retention in the arterial cells was suggested by Nikolai Anitschkow over 100 years ago (24). Enhanced plasma concentrations of cholesterol-rich apolipoprotein-B-containing lipoproteins are related to atherosclerosis. Lipoproteins can flux into and get out of the arterial wall via caveolin-1 and the scavenger receptor class B type I (SR-BI). Retention, or trapping, of cholesterol-rich apoB-containing lipoproteins within the arterial wall, is the key initiating event in atherogenesis. The retention of apoB-lipoproteins leads to lipid accumulation, triggers cellular responses within the artery wall, lesion development, maladaptive local responses, and plaque initiation $(25,26)$. The response-to-retention occurs via interacting lipoproteins with proteoglycans of the arterial wall (26). The consequences of the retention of apoB-lipoproteins include accumulation of lipids 
and exposure to local enzymes within the vessel wall (2729). Important enzymes involved in apoB-lipoprotein retention, aggregation, and atherogenesis are secretory sphingomyelinase (S-SMase), lipoprotein lipase, and phospholipase A2. The most action of these enzymes is accelerating further retention of atherogenic lipoproteins (26). Also, retention of cholesterolrich apoB-lipoproteins within the artery wall causes several modifications and significant biological consequences (26).

The major source of cholesterol and lipid accumulation in the arterial wall is proatherogenic mLDL (30). Desialylation, oxidation, formation of LDL self-associates, and LDL-containing immune complexes are the known LDL modifications (31). Also, all eight classes of scavenger receptors have been recognized as both native and modified LDL (32).

The first known atherogenic LDL modification is desialylation, and the trans-sialidase (neuraminidase) enzyme is responsible for LDL desialylation. The action mechanisms of intracellular lipid accumulation by desialylated LDL are performed in two ways; the first is binding, uptake, and degradation of LDL. The second is the evaluation of hydrolysis and esterification rates of lipids in LDL particles (33). LDL particles desialylation causes autoantibodies production, which forms circulating immune complexes (CIC) containing LDL (34). CIC causes the secretion of pro-inflammatory cytokines and macrophages apoptosis (34). Desialylated LDL causes the following consequences: lipid accumulation, enhancing its binding to the arterial proteoglycans, proliferative activity, connective tissue matrix components synthesis, breaking intercellular communication, chronic inflammation, and intracellular esterification of free cholesterol through preventing of the cholesterol acyltransferase esterifying activity in macrophages and cholesterol accumulation $(24,34)$.

Oxidative lipoprotein modification by intimal oxidizing agents, proteases, and lipases leads to the generation of oxidized phospholipids (oxPLs), inducing leukocyte recruitment, leukocyte activation, LDL aggregation, formation of cholesterol crystals, and inflammation (16).

Modified lipoproteins, such as ox-LDL, and LDL binding with proteoglycans of the extracellular matrix in the intima of blood vessels, cause aggregation of lipoprotein particles, endothelial damage, leukocyte recruitment, and inflammation (26). Then, foam cell forms from aggregated modified apoBlipoproteins through taking up oxidized, proteolyzed, or lipolysed lipoproteins, taking up cholesterol crystals by macrophages and taking up lipoproteins by SMCs via different classes of scavenger receptors (SR), such as SR class A (SR-A1, also known as CD204), SR class B (CD36), and the lectin-like oxidized LDL 1 receptor (LOX-1, or SR-E1), which can identify and bind to modified lipoproteins (35-37). Also, aggregated mLDL may accumulate in macrophages, which is recognized by low-density lipoprotein receptor-related protein 1 (LRP1) and Toll-like receptor 4 (TLR4) or degraded via lysosomal synapses (38-40).

SR-A is expressed on the surface of macrophages by regulating various factors. Sac1 and Sac3 phosphatases maintain a constant level of SR-A expression in the endoplasmic reticulum (41). Upregulation of Sac1 expression increases the SR-A receptor abundance. Tumor Necrosis Factor-alpha (TNF- $\alpha$ ) and Interleukin-6 (IL-6) can upregulate the SR-A expression leading to LDL accumulation by macrophages (42).

CD36 with its ligands (mLDL, HDL, fatty acids, and VLDL) is involved in lipoprotein uptake and lipid metabolism (43). Signaling pathways, such as non-receptor tyrosine kinase (SRC), cJun NH2-terminal kinase (JNK), Rac (GTPase) protein, and nuclear factor-kB (NF-kB transcription factor), are activated by interacting $\mathrm{mLDL}$ and CD36, which can result in LDL absorption, oxidative processes, and the production of proinflammatory cytokines $(32,44)$. LOX-1 from the E class SR family is involved in lipid accumulation, and its expression is increased in the intima under the inflammation and oxidative condition (32).

In the context of the response-to-retention, HDL has the following roles: interfering with the irreversible binding of plasma LDL to arterial wall proteoglycans, blocking SMaseinduced aggregation of LDL, omitting toxic lipids, ameliorating the maladaptive inflammatory infiltrate, inhibiting lipoprotein oxidation, EC protection and suppression of monocyte adhesion (45-49).

\section{Role of Inflammation in Atherosclerosis}

The role of inflammation in the pathogenesis of atherosclerosis was suggested in 1908 by Sir William Osler (50). Inflammation participates in all phases of atherosclerosis. For example, stable plaques and ruptured plaques are characterized by a chronic inflammatory infiltrate and "active" inflammation in the thinning of fibrous caps (21). Inflammation is linked with different risk factors of atherosclerosis $(26,51)$. All risk factors of atherosclerosis cause inflammatory response (9). Cellular cholesterol and inflammation can affect the immune system and autoimmune diseases (26).

Ox-LDL and generally modified lipoproteins increase endothelial damage, leukocyte recruitment, and inflammation. Several studies revealed that high levels of E-selectin, ICAM-1, and VCAM-1 are expressed by inflamed endothelium (52). Thus, these activated endothelial cells are the local source of leukocytes recruited into an atherosclerotic lesion (21). One of the earliest signs of atherosclerosis is endothelial dysfunction or activation (53). High inflammatory responses lead to arterial wall thickening (53).

Various inflammatory cells such as macrophage foam cells and $\mathrm{T}$ lymphocytes participate in inflammatory responses and the progression of atherosclerosis (21). Different cytokines are produced by macrophage foam cells leading to activation of SMCs and extracellular matrix production (8).

In the initiation phase of atherosclerosis, monocytes and lymphocytes migrate into the inner arterial wall with the help of MCP- 1 and T cell chemo-attractant. Inside the intima, monocytes are differentiated into macrophage foam cells under the influence of M-CSF. All activated cells release inflammatory cytokines and proinflammatory mediators. In the fatty-streak lesion, Tcells secrete TNF- $\beta$, IFN- $\gamma$, fibrogenic mediators, and growth factors that can cause the migration and proliferation of smooth muscle cells. Also, activated T-cells cause the following important inflammatory reactions: stimulating Matrix Metalloproteinase 
(MMP) production by macrophages in the lesion, producing IFN- $\gamma$, and halting collagen synthesis by the SMCs. It is considered that plaque formation is related to increased plasma concentration of C-Reactive Protein (CRP) (53). As mentioned above, inflammatory cells, macrophage foam cells and T-cells, and proinflammatory mediators (cytokines, interleukins) have important roles in all different stages of atherosclerosis.

Traditional risk factors of atherosclerosis are Hypercholesterimia, HDL, hypertension, obesity, and diabetes. The high level of LDL cholesterol in the blood causes artery and vascular smooth muscle cells (VSMCs) injury, induction of adhesion molecules and proinflammatory cytokines expression in macrophages and endothelial cells, and activation inflammatory response by expressing mononuclear leukocyte recruiting mechanisms (9).

The mechanisms of actions of HDL are inhibiting LDL oxidative modification, blocking the proinflammatory effects of ox-LDL, promoting antioxidant enzyme activity such as acetylhydrolase and paraoxonase, which neutralize oxidized lipids, and proinflammatory effects (9).

Angiotensin II (AII), as a powerful vasoconstrictor, is produced during hypertension (54). AII increases the growth of SMCs and facilitates smooth muscle lipoxygenase activity and results in speeding up inflammation. Also, it causes inflammation of endothelial intima via promoting the expression of cytokines (IL-6) and MCP-1 and superoxide anion production by the endothelium and SMCs of the artery $(9,54)$. In fact, Ang-II has pro-atherogenic effects and increases endothelial oxidative stress. Also, it up-regulates the LOX-1 gene and causes the activation of apoptosis pathways and induction of endothelial dysfunction (54).

Oxidative stress, ROS formation, endothelial activation, and disruption of cellular defense systems in conditions of chronic hyperglycemia and diabetes promote inflammation. Glycated lipoproteins protect the proinflammatory action of cytokines in the arterial endothelium $(55,56)$.

The elevated levels of VLDL and inflammatory processes can initiate atherosclerosis. Adiponectin, leptin resistin, TNF$\alpha$, and IL- 6 are cytokines generated from adipose tissue, which can impact inflammation (9). Biomarkers of inflammation or indicators of the inflammatory response are CRP, Protease Activated Receptor (PAR), CD40, Interleukin-18, LOX-1, and Lipoprotein-associated phospholipase (Lp-PLA2) (57). Obesity accelerates atherosclerosis through increasing glucose level, abnormal lipid profile, and systemic inflammation (58).

One of the most stable plasma biomarkers for low-grade systemic inflammation is CRP. It is a valuable tool for predicting, diagnosing, and prognosis of atherosclerosis. CRP has a direct role in promoting the inflammatory component of atherosclerosis. The significant mechanisms actions of CRP are: downregulating endothelial nitric oxide synthase (eNOS) to prevent nitric oxide releasing into the endothelium, destabilizing eNOS mRNA, increasing the release of endothelin (ET-1), adhesion molecules (VCAM-1, ICAM), MCP-1, migration of SMCs and facilitating LDL uptake by macrophage (59).

PAR has four types (PAR-1,-2,-3,-4). PAR-1 activation facilitates the binding of monocytes and leukocyte recruitment in the endothelium. PAR-1 and PAR-2 can enhance the leukocytes and platelets to the endothelium. It is proposed that the proinflammatory property of PARs is induced by IL- 1 and TNF- $\alpha$ in inflamed cells (9).

$\mathrm{CD} 40 / \mathrm{CD} 40 \mathrm{~L}$ is a proinflammatory system belonging to the TNF family. This protein is found in atherosclerotic plaques and expressed by activated macrophages, SMCs, vascular endothelial cells, and T lymphocytes. Binding of soluble CD40L (sCD40L), derived from activated platelet, to CD40 on SMC, and endothelium causes endothelial dysfunction, inflammation, and production of proinflammatory cytokines (IL-6, IL-1), VCAM1, ICAM, MCP-1, MMPs, fibroblast growth factor, vascular endothelial growth factor, platelet activation, and thus the production of ROS and RNS (9, 60-62).

Interleukin-18 (IL-18) is made by monocytes and macrophages and its receptor is expressed on $\mathrm{T}$ lymphocytes ( $\mathrm{T}$ helper). IL-18 binds to its receptors and causes inflammation and plaque formation via producing IL-1, TNF- $\alpha$, and a positive feedback mechanism. The stability of plaque is reduced by increasing MMP expression (9). This proinflammatory cytokine causes induction of IFN- $\gamma$, inhibiting collagen synthesis, preventing thick fibrous cap formation, and facilitating plaque destabilization (63).

LOX-1 is found in endothelial cells, macrophages, and SMCs. It is bound only to ox-LDL and detected in all phases of atherosclerosis. The ox-LDL/LOX-1 complex causes the following impacts: increasing ROS production, death of SMCs, MMP influence on a fibrous cap, providing a route of entry for ox-LDL into endothelium, disrupting the normal endothelial function and monocyte adhesion, and infiltration. The stimulation of LOX-1 causes endothelial dysfunction, leukocyte adhesion, collagen degradation, and foam cell formation (64). LpPLA2 has performed its proinflammatory and proatherogenic functions by promoting monocyte chemotaxis, enhancing expression of mononuclear leukocyte adhesion molecules in endothelial cells, producing lysophosphatidylcholine (lysoPC) and non-esterified fatty acid moieties (9).

\section{The Cellular Mechanisms of Inflammation and Lipid Accumulation in the Pathogenesis of Atherosclerosis}

The intimal layer of the arterial wall is the location of the Atherosclerotic lesion. The endothelial cells separate the intima from the lumen of the vessel. Under the basal membrane, different types of cells such as macrophages, dendritic cells, foam cells, lymphocytes, and other inflammatory cells are found in intimal atherosclerotic lesions (65). Deeper layers include SMCs and pericytes that participate in immunity reactions. Pericytes secrete pro-inflammatory cytokines such as IL-1, IL6 , and TNF. They also act as phagocytes and antigen-presenting cells $(66,67)$. Lesion development is associated with a local enhancement of the number of macrophages, loss of intercellular communication, and changes of Pericytes, macrophages, and SMCs phenotype (68).

Lipid droplets accumulate in the cytoplasm of Pericytes, macrophages, and SMCs and lead to change their appearance. 
The presence of Pericytes, macrophages, and SMCs in the subendothelial space of the arterial wall is an early manifestation of atherosclerosis (68). Atherogenic mLDL is the primary source of lipids that are found in foam cells and the circulation of atherosclerotic patients. Atherogenic modification of LDL is mentioned in section 3.1. mLDL stimulates phagocytosis by pericytes and macrophages. Then inflammatory cytokines are secreted, which causes the attraction of immune cells to the location of the inflammation. Inflammatory cytokines cause the accumulation of intracellular lipids. Intracellular lipids accumulation leads to rupture of the cells (68). Also, increasing proliferative activity and stimulation of extracellular matrix synthesis are occurring in the phase of inflammatory reaction (69). Based on current consensus, endothelial activation and enhanced permeability is the key event in the atherosclerotic lesion development. Endothelial cells express cytokines and chemokines (IL-1, TNF- $\alpha$, MCP-1, growth factors, and adhesion molecules). This leads to the interaction of circulating immune cells with endothelium and enhancement of the pro-inflammatory signaling at the emerging lesion site (68). As a result of the increase of pro-inflammatory cytokines, endoplasmic reticulum stress in the arterial wall cells and apoptosis have occurred (70). This process and cytokineinduced inflammation lead to interrupt the normal activity of mitochondria and then impaired mitophagy and apoptosis (71). mtDNA mutations have an important role in atherosclerosis. These mutations lead to impaired glucose and fat metabolism, increased oxidative stress, ROS generation, and cell death (68). ROS act as modulators of gene expression related to atherosclerosis development. The mutation spectrum of the mitochondrial genome is useful for the early detection of atherosclerosis $(3,71-74)$.

Lysosome function is linked to inflammatory cytokine release and regulation of immune response. So, loss of lysosomal function in ox-LDL-loaded Macrophages is a general effect related to the excess lipid loading during atherosclerosis $(75,76)$.

\section{The Role of Long Non-coding RNAs in Lipid Accumulation and Inflammation}

Long non-coding RNAs (lncRNAs) have been considered as a novel group of epigenetic regulators with significant roles in the pathogenesis and development of atherosclerosis. Also, these biomarkers have the potential for targeting them therapeutically (77). IncRNAs have multiple functions in a wide range of biological processes. They are involved in regulating macrophage, lipid metabolism and inflammatory, and immune responses (78, 79).

Taurin-up-regulated gene 1 (TUG1) knockdown prevents hyperlipidemia and atherosclerotic lesions through upregulating the miR-133a expression which targets the fibroblast growth factor 1 (FGF1) (80, 81). LncRNA-H19 has influenced lipid metabolism by targeting miR-130b. It suppresses lipid metabolism and increases lipid accumulation which causes lipid metabolic disorders and atherosclerosis $(79,82)$. IncRNA-H19 knockdown decreases inflammatory responses and proinflammatory factors (IL-1 $\beta$, IL-6, and TNF- $\alpha$ ) and enhances the expression of anti-inflammatory factors (IL-4 and IL-10). So, H19 can prevent endothelial inflammation by inhibiting the STAT3 (signal transducer and activator of transcription 3) signaling pathway (82-84). IncRNA RP5-833A20.1 has a regulatory function in lipid metabolism and inflammation during atherosclerosis. Its target is miR-382. This lncRNA causes enhancement of inflammatory cytokines (TNF- $\alpha$, IL-1 $\beta$, and IL-6) and decreases cholesterol efflux via the miR-382-mediated Nuclear factor I A (NFIA) pathway, and attenuates ATP binding cassette transporter A1 (ABCA1) levels (85). lncRNA E330013P06 is a new pro-inflammatory long non-coding RNA. MiR143/145 is a key target of this lncRNA. Overexpressing E330013P06 promotes foam cell formation via increasing inflammatory genes (Nos2, Il6, and Ptgs2) and scavenger receptor CD36 (78). IncRNA growth arrest-specific 5 (GAS5) regulates atherosclerosis developments via various mechanisms including promoting monocyte migration, interaction with the histone methyltransferase EZH2 (enhancer of zeste homolog 2) PRC-2 subunit, decreasing ABCA-1 expression, cholesterol efflux, and producing of inflammatory cytokines via targeting miR-221 and up-regulating MMP-2 and MMP-9 $(86,87)$. Antisense non-coding RNA in the INK4 locus (Anril), or CDKN2B antisense RNA 1 (CDKN2B-AS1), has different effects on lipid metabolism and inflammation in atherosclerosis. It can promote lipid uptake and LPS induced-inflammation via regulating the $\mathrm{CDKN} 2 \mathrm{~B}$ promoter and activating the NF-kB signaling pathway $(4,88,89)$. Knocking down of long noncoding RNA Maternally Expressed Gene 3 (MEG3) protects the VSMCs from ox-LDL-induced injury by enhancing p53 expression (90). Also, it increases pyroptosis by sponging miR-223 and targeting NOD-like receptor protein 3 (NLRP3). Also, the ox-LDL-induced apoptosis in VSMCs by sponging the miR-361-5p. So, MEG3 promotes the development of atherosclerosis by increasing inflammation (91-93). Long non-coding RNA-DAPK1-IT1 decreases ABCA1 and ATPbinding cassette transporters G1 (ABCG1) protein levels in THP-1 macrophages by sponging miR- 590-3p and targeting lipoprotein lipase (LPL). Thus, it reduces the levels of HDL and enhances the levels of LDL (94).

Long non-coding RNA metastasis-associated lung adenocarcinoma transcript 1 (MALAT1) has a protective effect against atherosclerosis lesions. The supportive effects of MALAT1 against the ox-LDL-induced apoptosis were performed through these action mechanisms: Upregulating endothelial-tomesenchymal transition (EndMT), competing with miR-22-3p, induction of autophagy by inhibiting the PI3K/AKT pathway or sponging miR-216a-5p, and suppressing the production of ox-LDL mediated pro-inflammatory cytokines such as IL-6 and IL-8 via sponging miR-155 (95-98). The anti-inflammatory effect of MALAT1 is increasing lipid uptake in macrophages via interacting with nuclear enriched abundant transcript (NEAT1) (99, 100). IncRNA myocardial infarction associated transcript (MIAT) has a protective effect against the ox-LDL-induced apoptosis through inhibiting miR-181b and signal transducer and activator of transcription 3 (STAT3) (101, 102). From a therapeutic point of view, lncRNA-DYNLRB2-2 has antiatherosclerotic properties via different mechanisms, including 
TABLE 1 | A list of IncRNAs involved in lipid accumulation and inflammation.

\begin{tabular}{|c|c|c|c|c|}
\hline IncRNA & $\begin{array}{l}\text { Biological } \\
\text { processes }\end{array}$ & Target & Function & Reference \\
\hline MALAT1 & $\begin{array}{l}\text { Leukocyte } \\
\text { activation, cholesterol } \\
\text { metabolism }\end{array}$ & $\begin{array}{l}\text { miR-216a-5p, miR-155 and } \\
\text { miR-22-3p }\end{array}$ & Inhibiting inflammation & $(95-100)$ \\
\hline MIAT & $\begin{array}{l}\text { Macrophage } \\
\text { apoptosis }\end{array}$ & miR-181b/STAT3 & Apoptosis, inhibiting inflammation & $(101,102)$ \\
\hline GAS5 & $\begin{array}{l}\text { Cholesterol } \\
\text { metabolism }\end{array}$ & miR-221, MMP-2 and MMP-9 & Promoting inflammation & $(86,87)$ \\
\hline DYNLRB2-2 & Cholesterol metabolism & ABCA1 and TLR2 & Inhibiting inflammation and increasing cholesterol efflux & $(4,103-105)$ \\
\hline Anril & $\begin{array}{l}\text { Endothelial } \\
\text { dysfunction; } \\
\text { cholesterol } \\
\text { metabolism }\end{array}$ & ADAM10 and CDKN2B & Promoting lipid accumulation and inflammation & $(4,88)$ \\
\hline DAPK1-IT1 & Cholesterol metabolism & miR- 590-3p and LPL & Promoting lipid accumulation and inflammation & $(94)$ \\
\hline MEG3 & Lipid metabolism & miR-223 and miR-361-5p & Increasing inflammation and pyroptosis & $(90-93)$ \\
\hline E330013Р06 & Lipid metabolism & miR-143 and miR-145 & Promoting inflammation and foam cell formation & $(78)$ \\
\hline RP5-833A20 & $\begin{array}{l}\text { Cholesterol } \\
\text { metabolism }\end{array}$ & miR-382 & Promoting inflammation/decreasing cholesterol efflux & (85) \\
\hline $\mathrm{H} 19$ & $\begin{array}{l}\text { Endothelial } \\
\text { dysfunction }\end{array}$ & miR-130b & Increasing lipid accumulation, and Inflammation & $(82-84)$ \\
\hline TUG1 & $\begin{array}{l}\text { Endothelial } \\
\text { dysfunction; } \\
\text { Macrophage } \\
\text { apoptosis }\end{array}$ & miR-133a/FGF1 & $\begin{array}{l}\text { Promoting lipid accumulation, } \\
\text { inflammation and apoptosis }\end{array}$ & $(80,81)$ \\
\hline
\end{tabular}

promoting cholesterol efflux, inhibiting inflammation, increasing ABCA1 expression, inhibiting THP-1 macrophage foam cell formation, activating the LKB1/AMPK/mTOR signaling pathway, and inhibiting the lipopolysaccharide (LPS)-induced inflammatory cytokines such as TNF-a, IL-1b, and IL-6 in macrophages by reducing TLR2 expression (4, 103-105). From a therapeutic point of view, Anril causes cholesterol efflux and reduction of inflammatory cytokines such as IL-1b and TNF- $\alpha$ in ox-LDL-exposed THP-1 macrophages via inhibiting a disintegrin and metalloprotease (ADAM) expression (106). The most important lncRNAs involved in lipid accumulation and inflammation are summarized in Table $\mathbf{1}$ and Figure $\mathbf{1}$.

\section{Role of microRNAs in Lipid Accumulation and Inflammation}

MicroRNAs have appeared as key regulators of several physiological and pathophysiological processes in atherosclerosis including regulation of HDL biogenesis, cholesterol efflux, lipid metabolism, regulating of smooth muscle proliferation, and controlling of inflammation through the activation and infiltration of leukocytes via the vascular wall (108-110). Moreover, numerous studies have demonstrated the beneficial role of miRNAs as therapeutic targets in the treatment of atherosclerosis and cardiovascular disease (Table 2 and Figure 1) (131).

The overexpression of miR-146a can inhibit the activation of the TLR4 signaling pathway and prevent ox-LDL accumulation (116). Overexpression of miR-146a significantly decreases intracellular LDL cholesterol content and secretion of IL-6 and IL-8, chemokine (C-C motif) ligand-2, and MMP9 in macrophages by targeting CD40L $(116,117)$. It was demonstrated that miR-146a regulates IL-1 receptor-associated kinase-1 (IRAK1) and TNF-receptor-associated factor-6 (TRAF6) (118). The protective role of miR-125a-5p against atherosclerosis was performed through regulating the proinflammatory response, lipid uptake by macrophages, decreasing content of the inflammatory cytokines: tumor growth factorbeta (TGF- $\alpha$ ), TNF- $\alpha$, IL-2, and IL-6 (115). The miR-125a-5p expression can cause the expression of LOX-1 and CD68 leading to a decrease of ox-LDL-stimulated macrophage uptake (115). Thus, it suppresses oxysterol binding protein like-9 (ORP9) and leads to reduction of lipid uptake and the secretion of inflammatory cytokines, including IL-2, IL-6, TNF- $\alpha$, and TGF- $\beta$, in ox-LDL stimulated human primary monocytes (115). miR-223 is one of the most abundant miRs in LDL and HDL particles and inflammation (128). NOD-like receptor pyrin domain containing 3 (NLRP3) and ICAM-1 are the targets of miR-223. Upregulation of both these targets increases endothelial inflammation and causes leukocyte infiltration and inflammation connected with atherosclerosis $(129,130)$. It inhibits cholesterol biosynthesis via suppressing the sterol enzymes 3-hydroxy-3methylglutaryl-CoA synthase 1 (HMGCS1) and methylsterol monoxygenase 1 (MSMO1) in humans (131). miR-10a upregulation can influence inflammation through decreasing I $\kappa / \mathrm{NF}-\kappa \mathrm{B}$ activation, downregulation of inflammatory biomarkers, such as MCP-1, VCAM-1, E-selectin, IL-6, and IL-8. So, it suppresses inflammatory molecules in endothelial cells 


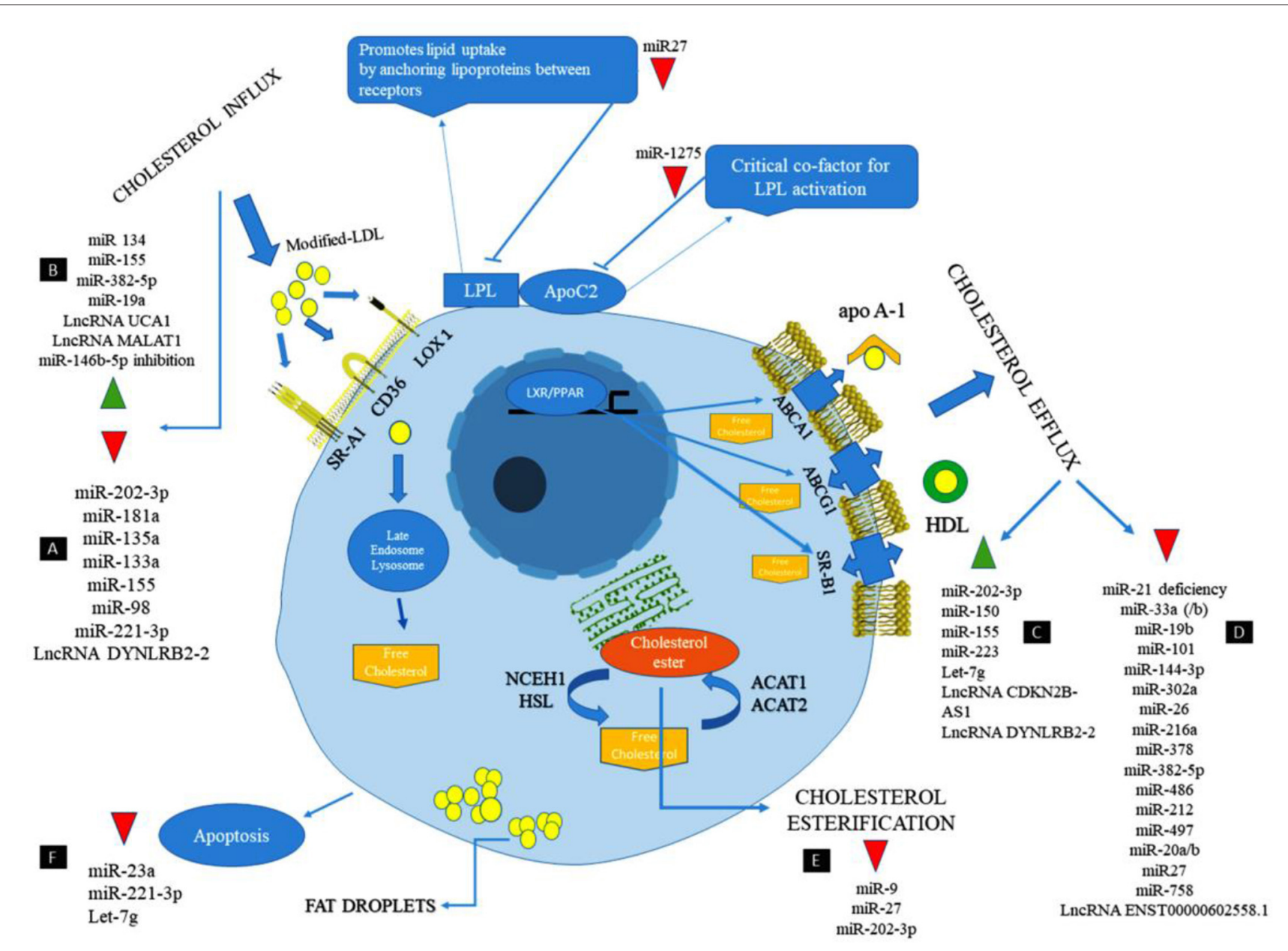

FIGURE 1 | The cellular mechanism of atherosclerosis and the involvement of non-coding RNAs in this process (107).

TABLE 2 | A list of microRNAs involved in lipid accumulation and inflammation.

\begin{tabular}{|c|c|c|c|}
\hline miRNA & Target & Function & Reference \\
\hline miR-155 & MAPK10/SOCS1 & Decreasing inflammation, lipid uptake and foam cell formation & $(111-114)$ \\
\hline $\operatorname{miR}-125 a-5 p$ & ORP9 & Reduction of lipid uptake and secretion of inflammatory cytokines & $(115)$ \\
\hline $\operatorname{miR}-146 a$ & $\begin{array}{l}\text { TNF receptor (TNFR) } \\
\text { associated factor } 6 \\
\text { (TRAF6) }\end{array}$ & Decreasing intracellular LDL cholesterol content and inflammation & $(116-118)$ \\
\hline $\mathrm{miR}-33 \mathrm{a} / \mathrm{b}$ & ABCA-1 & $\begin{array}{l}\text { HDL biogenesis and reverse } \\
\text { cholesterol transport }\end{array}$ & $(119,120)$ \\
\hline miR-34a & SirT1 & Inducing endothelial cell senescence and inhibiting cell cycle & $(121)$ \\
\hline miR-10a & MAP3K7 & Inhibits NF-kB activation and down regulation of inflammatory molecules & $(122)$ \\
\hline miR-302a & ABCA1 & HDL biogenesis, cholesterol efflux and inhibiting foam cell formation & $(77)$ \\
\hline miR-126 & VCAM-1 & Inhibiting angiogenesis and inflammation & $(123-125)$ \\
\hline $\operatorname{miR}-21$ & MKK3 & Cholesterol efflux and inhibiting foam cell formation & $(21,126)$ \\
\hline miR-92a & STAT3 & Increasing inflammation & $(127)$ \\
\hline miR-223 & ICAM-1 and NLRP3 & Reducing foam cell formation and production of proinflammatory cytokines & $(128-130)$ \\
\hline
\end{tabular}

(122). miR-21 is a vital signaling mediator in an inflammatory state. Inhibition of this miRNA is related to the progression of atherosclerosis via increasing expression of mitogen-activated protein kinase kinase 3 (MKK3), inducing both $\mathrm{p} 38$ and the JNK (c-Jun $\mathrm{N}$-terminal kinase) signaling pathway and regulating the expression of different pro-inflammatory mediators, including 
lipopolysaccharides and TNF- $\alpha$ (126, 132). miR-302a can regulate $\mathrm{ABC}$ transporters, which are involved in cholesterol efflux. The action mechanisms of this miRNA are increasing ABCA1 activity, cholesterol efflux out of macrophages, and preventing foam cell formation and growth of the atheromatous plaque (77). miR-126 can affect the inflammatory state of vasculature by the activation and infiltration of leukocytes via the vascular wall. It inhibits VCAM-1. Thus, miR-126 inhibition leads to enhancement of the proinflammatory TNF- $\alpha$ expression, the activity of NF- $\kappa \mathrm{B}$ (nuclear factor $\kappa \mathrm{B}$ ), the activity of VCAM-1, as well as leukocyte-endothelial cells interactions and atherosclerotic lesions formation (123-125). Overexpression of miR-155 can cause attenuated inflammation and the subsequent foam cell formation via miR-155/calcium-regulated heat-stable protein 1 (CARHSP1)/TNF- $\alpha$ signaling pathway and targeting of mitogen-activated protein kinase 10 (MAPK10) signaling pathway $(111,112)$. It was suggested that miR-155 can contribute to the inflammatory processes through increasing STAT3 and nuclear factor kappa-light-chain-enhancer of activated B cells (NF-kB) signaling and targeting the suppressor of cytokine signaling 1 (SOCS1) in ox-LDL-induced macrophages (113). miR-155 could decrease the lipid uptake in ox-LDL-stimulated cells (114). miR-33a/b is a key regulator of lipid metabolism. It plays a key role in regulating reverse cholesterol transport by inhibiting the expression of ABCA1 at the RNA and protein level and decreasing cellular cholesterol efflux to apolipoprotein A-I (ApoA-I) $(119,120)$. Inhibition of miR-33a/b causes the following consequences: Increasing $\beta$-oxidation and decreasing fatty acid synthesis, ameliorating circulating lipids profile, and slowing down the progression of atherosclerosis $(119,120)$.

miR-92a expression in the endothelial cells of atherosclerosisprone areas is an important regulator of atherosclerosis development via targeting STAT3 and secreting IL-6 and MCP1 (127). miR-34a can develop atherosclerosis via inhibiting cell cycle and SirT1 protein expression, inducing endothelial cell senescence and repressing cell proliferation (121).

\section{Role of Medicinal Plants and Their Active Compounds in Atherosclerosis}

In recent decades, medicinal plants and natural products have been considered as one of the most important antiatherosclerotic strategies for the treatment and prevention of atherosclerosis. Medicinal plants and natural products with their potential antioxidant, antiatherogenic, and anti-thrombotic properties, prevent atherosclerosis and its harmful complication through modulating the pathways of the inflammatory response, reducing cholesterolemia, free radicals, and decreasing vascular resistance $(133,134)$. The most important medicinal plants with anti-atherosclerotic actions have been summarized in Table 3 and Figure 2.

The experimental New Zealand rabbits group treated with extract of Tribulus terrestris revealed decreased levels of total cholesterol (TC), high-density lipoprotein cholesterol (HDL-C), low-density lipoprotein cholesterol (LDL-C), and triglyceride (TG) in serum compared to the control group $(133,157)$. In Triton WR-1339-induced hyperlipidemic rats treated with
Ocimum basilicum extract, the TC, TG, and LDL-C levels decreased (133, 158). Salvia miltiorrhiza with its Salvianolic acid B can inhibit CD36-mediated lipid uptake via binding directly to CD36 with high affinity (159). Salvia miltiorrhiza and cryptotanshinone decrease the expression of MMP-9, NF$\kappa \mathrm{B}$, and the production of adhesion molecules. This plant prevents the migration of human aortic smooth muscle cells (174, 175). Salvia miltiorrhiza and its active compound, Danshenol, suppress ICAM-1 expression and relevant monocyte adhesion to endothelial cells through the NADPH oxidase subunit 4 (NOX4)-dependent inhibitor of kappa B (IкB) kinase $\beta(\mathrm{IKK} \beta) /$ nuclear factor-kappa $\mathrm{B}(\mathrm{NF}-\kappa \mathrm{B})$ pathway (164). Cryptotanshinone from S. miltiorrhiza decreased LOX1, ICAM-1, and VCAM-1 expression (135, 136). Salvianolic acid B from Salvia miltiorrhiza reduced JAK2 (Tyr 1007/1008) and STAT1 (Tyr701 and Ser727) phosphorylation. It enhanced protein inhibitor of activated STAT 1 (PIAS1) and suppressor of cytokine signaling 1 (SOCS1) expressions in endothelial cells (176). The modulatory effects of salvianolic acid B and Cryptotanshinone, bioactive compounds from S. miltiorrhiza, significantly suppressed the atherosclerotic plaque formation by inhibiting the LOX-1 and MMP-9 expression and affecting PI3K/Akt, MAPK, NF-KB pathways $(135,137)$. Allium sativum with large amounts of flavonoids, such as kaempferol inhibits cyclooxygenase and lipoxygenase and prevents the accumulation of thrombocytes. Allium sativum extract decreases the level of malondialdehyde, superoxide, and hydroxyl radicals (141). Allium sativum has antithrombotic activity by suppressing cyclooxygenase, reducing the generation of thromboxane B2, prostaglandin E2, and leukotriene C4 by platelets (142). Extract from Allium sativum inhibits platelet aggregation via different mechanisms including increasing cyclic nucleotides, inhibiting GPIIb/IIIa receptor and fibrinogen binding, and preventing phosphorylation of collagen-induced ERK, JNK, and p38 (143145). It lowers blood lipids such as total cholesterol and triglycerides through down-regulating acetyl-CoA carboxylase (ACC), acyl-CoA cholesterol acyltransferase (ACAT), HMGR, fatty acid synthase (FAS), sterol regulatory element-binding protein-1c (SREBP-1c), and glucose-6- phosphate dehydrogenase (G6PD) (170). Nigella sativa and its main active compounds, propolis and thymoquinone, prevent LDL oxidation and decrease in the development of atherosclerotic lesions. It scavenges the free radicals and has antioxidant activity. This medicinal plant and its active compounds decreased TC, LDL-C, and TG, while increased HDL-C levels in hypercholesterolemic rabbits $(162,163)$. Celastrus orbiculatus up-regulated scavenger receptor class B type 1 (SR-B1), cholesterol $7 \alpha$-hydroxylase A1 (CYP7A1), and 3-hydroxy-3-methyl-glutaryl-coenzyme A (HMG-CoA) reductase and significantly decreased TC, nonHDL-C, TG, and lipid deposition in the arterial wall (160). C. orbiculatus decreased CRP, IL-6, and TNF- $\alpha$ levels in plasma and CD68 up-regulation and NF-кB p65 protein activation in the arterial wall (160). Magnolia officinalis, with its main compound, magnolol, suppressed IL-6-induced phosphorylation of Tyr705 and Ser727 on STAT3. STAT3 is a transcription factor involved in inflammatory responses. It reduces ICAM1 expression on the endothelial surface (151). The ethanolic 
TABLE 3 | Important anti-atherosclerotic medicinal plants and compounds.

\begin{tabular}{|c|c|c|c|}
\hline Medicinal plants & Active compounds & Action mechanism & Reference \\
\hline \multicolumn{4}{|c|}{ Anti-inflammatory effects of medicinal herbs } \\
\hline Salvia miltiorrhiza & Salvianolic acid B and cryptotanshinone & $\begin{array}{l}\text { Decreasing expression of MMP-9 and inhibition of NF-kB pathway and } \\
\text { ICAM-1,VCAM-1 and MCP-1 expression }\end{array}$ & $(135-137)$ \\
\hline Glycyrrhiza glabra & glabridin & $\begin{array}{l}\text { Blockage of JNK and NF-kB signaling, suppression of TNF-a, and production of } \\
\text { IL-1b }\end{array}$ & $(138-140)$ \\
\hline Allium sativum & kaempferol & Inhibiting of inflammation signaling (like TNF-a, IL-1b, ICAM-1) & $(141-145)$ \\
\hline Punica granatum & Ellagic acid and punicalagin & Decreasing plasma levels of IL- 6 and TNF- $\alpha$ and increasing IL-10 & $(148-150)$ \\
\hline Magnolia offinicalis & Magnolol & $\begin{array}{l}\text { Suppressing phosphorylation of Tyr705, Ser727 and Tyr705 and stat3, inhibition } \\
\text { of NF-kB pathway and inhibition of adhesion molecules expression }\end{array}$ & $(151)$ \\
\hline Curcuma wenyujin & $\beta$-Elemene & Inhibiting production of IL-1 $\beta$, TNF- $\alpha$, INF- $\gamma$, MCP-1, and ICAM-1 & $(152)$ \\
\hline Tripterygium wilfordii & Celastrol & Decreasing production of iNOS, NO, and pro-inflammatory cytokines & (153) \\
\hline Coptis chinensis & berberine & NF-kB activation and JNK phosphorylation & (156) \\
\hline \multicolumn{4}{|l|}{ Lipid-lowering effects } \\
\hline Tribulus terrestris & Tribulus terrestris extract & Decreasing total cholesterol, LDL-C, and triglyceride (TG) & $(133,157)$ \\
\hline Ocimum basilicum & Aqueous extract of Ocimum basilicum & Decreasing total cholesterol, LDL-C, and triglyceride (TG) & $(133,158)$ \\
\hline Salvia miltiorrhiza & Salvianolic acid B & Inhibiting CD36 and decreasing total cholesterol, LDL-C, and triglyceride (TG) & (159) \\
\hline Celastrus orbiculatus & Celastrus orbiculatus extract & $\begin{array}{l}\text { Up regulating SR-B1, CYP7A1 and HMG-CoA, decreasing total cholesterol, } \\
\text { LDL-C, and triglyceride (TG) }\end{array}$ & $(160)$ \\
\hline Panax notoginseng & saponins & Decreasing total cholesterol, LDL-C, and triglyceride (TG) & $(161)$ \\
\hline Nigella sativa & Propolis and thymoquinone & Decreasing total cholesterol, LDL-C, and triglyceride (TG) & $(162,163)$ \\
\hline Astragalus membranaceus & Astragaloside IV & Increased activity of PPAR $\alpha$ and PPAR $\gamma$ & $(146,147)$ \\
\hline Allium sativum & Flavonoids, alkaloids & Decreasing total cholesterol, LDL-C, and triglyceride (TG) & $(141-145)$ \\
\hline Celastrus orbiculatus & C. orbiculatus extract & Inhibiting ROS production & $(160)$ \\
\hline Tripterygium wilfordii & Celastrol & Inhibiting ROS production and LOX-1 and iNOS expression & (153) \\
\hline Ocimum basilicum & Aqueous extract of Ocimum basilicum & Inhibiting Radical anion superoxide production & $(133,158)$ \\
\hline G. glabra & Glycyrrhizin and glabridin & $\begin{array}{l}\text { Inhibiting ROS production, inhibiting LDL NADPH oxidase and preventing } \\
\text { cholesterol oxidation }\end{array}$ & $(138-140)$ \\
\hline A. sativum & Flavonoid, kaempferol & Decreasing lipid peroxidation, superoxide and hydroxyl radicals & $(141-145)$ \\
\hline Sesamum indicum & Sesamolinol, sesamol & Inhibiting ADP-Fe+/NADH-induced peroxidation and lipid oxidation & $(165,166)$ \\
\hline \multicolumn{4}{|c|}{ Suppression of cholesterol accumulation and foam cell formation } \\
\hline Curcuma longa & curcumin & $\begin{array}{l}\text { Promoting ABCA1-dependent cholesterol efflux and inhibiting of SR-A-mediated } \\
\text { oxidized LDL uptake }\end{array}$ & $(167-169)$ \\
\hline Coptis chinensis & berberine & $\begin{array}{l}\text { Increasing LXRa-ABCA1-dependent cholesterol efflux, activating the } \\
\text { AMPK-SIRT1-PPAR-?pathway and down-regulating HMGR expression }\end{array}$ & (156) \\
\hline Allium sativum & kaempferol & $\begin{array}{l}\text { Down-regulation of HMGR, FAS, SREBP-1c, G6PDH and acetyl-CoA } \\
\text { carboxylase }\end{array}$ & $(170)$ \\
\hline Salvia miltiorrhiza & Salvianolic acid B & Down-regulating of CD36 expression & (159) \\
\hline Punica granatum & Ellagic acid and punicalagin & Up-regulation of $A B C A 1$ expression and regulating PPAR-ABCA1 pathway & $(148-150)$ \\
\hline \multicolumn{4}{|c|}{ Inhibitory effects of medicinal herbs against monocyte recruitment } \\
\hline Purple perilla & Purple perila extract and $\alpha$-asarone & $\begin{array}{l}\text { Inhibiting foam cell formation and SR-B1 expression, upregulation of ABCA1 and } \\
\text { ABCG1 }\end{array}$ & $(133,171)$ \\
\hline
\end{tabular}


TABLE 3 | Continued

\begin{tabular}{|c|c|c|c|}
\hline Medicinal plants & Active compounds & Action mechanism & Reference \\
\hline Buddleja officinalis & Aqueous extract of Buddleja officinalis & Inhibiting VCAM-1 and ICAM-1 expression & $(156)$ \\
\hline Curcuma longa & curcumin & Inhibiting $\left.\right|_{\kappa} B \alpha$, Akt, and PKC phosphorylation and VCAM-1 expression & $(167-169)$ \\
\hline Salvia miltiorrhiza & Cryptotanshinone & Reducing LOX-1, VCAM-1 and ICAM-1 expression & $(136,164)$ \\
\hline Paeonia lactiflora & Paeonol & Inhibiting ICAM- 1 expression and NF-кB p65 translocation into the nucleus & $(172)$ \\
\hline Panax notoginseng & Saponins & Inhibiting ICAM- 1 and VCAM-1 expression & $(161)$ \\
\hline
\end{tabular}

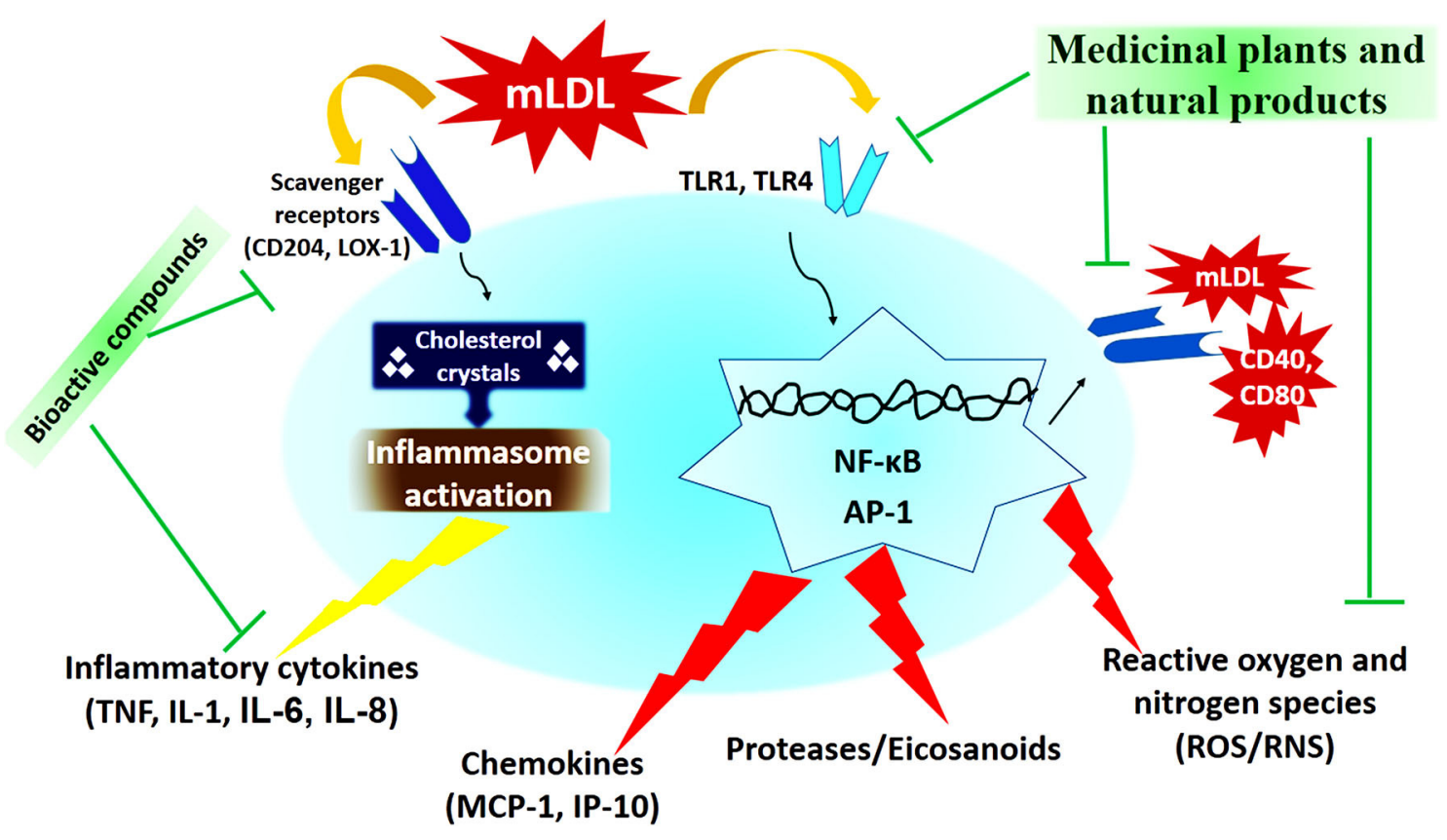

FIGURE 2 | The cellular mechanism of atherosclerosis development and mechanisms of action of medicinal plants and natural products (173).

extract of Astragalus membranaceus decreased blood glucose and triglyceride (TG) via the increasing activity of PPAR- $\alpha$ and PPAR- $\gamma$ (146). Also, downregulation of CD40 ligand and C$\mathrm{X}-\mathrm{C}$ chemokine receptor type 4 (CXCR4) expression on the platelet surface, and stromal cell-derived factor-1 (SDF-1) and CXCR4 expression in the aorta are the most important effects of A. membranaceus and Astragaloside IV (147). $\beta$-Elemene isolated from Curcuma wenyujin inhibits the production of pro-inflammatory cytokines and cell adhesion molecules such as IL- $1 \beta$, TNF- $\alpha$, INF- $\gamma$, MCP- 1 , and ICAM- 1 and decreases the size of atherosclerotic lesions (152). Tripterygium wilfordii and its triterpenoid, Celastrol, prevent phosphorylation and degradation of I $\mathrm{B}$. This medicinal plant reduces the production of inducible nitric oxide synthase (iNOS), NO, and proinflammatory cytokines such as TNF- $\alpha$ and IL-6 (153). Curcuma longa and curcumin inhibit SR-A-mediated oxidized LDL uptake and lead to reduced cholesterol accumulation in the arterial wall via activation of the AMPK-SIRT1- LXRa signaling pathway $(167,168)$. Also, curcumin shows anti-inflammatory properties via inhibiting the activity of iNOS, COX-2, lipoxygenase, and xanthine oxidase, and activating NF-kB (169). C. longa inhibits
I $\mathrm{B} \alpha$, protein kinase $\mathrm{B}$ (Akt), and protein kinase C (PKC) phosphorylation and suppresses VCAM-1 expression (155). Glycyrrhiza glabra and its main flavonoid, glabridin, have anti-inflammatory properties via different action mechanisms including inhibiting TNF-a-stimulated gene expression of VCAM-1 and ICAM-1 and blocking JNK and NF-kB (138, 139). It prevents LDL oxidation through inhibiting 2, 2azobis (2-amidinopropane) hydrochloride (AAPH)-stimulated production of cholesteryl linoleate hydroperoxide in LDL (140). Coptis chinensis and its main compound, berberine, increase LXRa-ABCA1-dependent cholesterol efflux and activate the AMPK-SIRT1-PPAR-g pathway, consequently decreasing foam cell formation (156). Punica granatum, ellagic acid, and punicalagin, possess obvious anti-inflammatory effects including reducing plasma levels of IL- 6 and TNF- $\alpha$, increasing the antiinflammatory cytokine IL-10, and decreasing the translocation of NF-kB from the cytosol to the nucleus (148-150). Ginkgo biloba extract decreases IL- $1 \beta$, TNF- $\alpha$, IL-10 expression, and growth of vascular smooth muscle cells (VSMC) (154).

Paeonol, the active compound of Paeonia lactiflora, decreased ICAM- 1 expression via phosphorylation of I $\mathrm{B} \alpha$ and inhibition 
of NF-кB p65 translocation into the nucleus. It had influences on extracellular signal-regulated kinase (ERK) induced by TNF$\alpha$ and blocked the phosphorylation of p38 (172). Saponins, the active compounds of Panax notoginseng suppress TNF$\alpha$-induced endothelial adhesion molecules such as ICAM-1 and VCAM-1 expression and reduce monocyte adhesion to the endothelium (161). Purple perilla and its main compound $\alpha$-asarone prevent ox-LDL-induced foam cell formation via inhibiting SR-B1 expression. Also, Purple perilla causes the adenosine triphosphate (ATP)-binding cassette transporter A1 (ABCA1) and ABCG1 upregulation, and subsequently result in cholesterol efflux from macrophages through interactions between peroxisome proliferator-activated receptor $\gamma$ (PPAR $\gamma$ ), liver $\mathrm{X}$ receptor $\alpha(\mathrm{LXR} \alpha)$, and $\mathrm{ABC}$ transporters (133). Buddleja officinalis reduces VCAM-1 and ICAM-1 through inhibition of NF- $\mathrm{B}$ and reactive oxygen species (ROS) (156). Sesamum indicum with its antioxidant and anti-inflammatory properties showed inhibitory effects on membrane microsomal peroxidation, lipid peroxidation, $\mathrm{ADP}-\mathrm{Fe}^{3+} / \mathrm{NADH}$-induced peroxidation, and $\mathrm{Cu}$ ions-induced LDL oxidation. Hence, this plant decreases the levels of plasma triglyceride and cholesterol, and LDL-cholesterol (LDL-C) $(165,166)$.

\section{CONCLUSIONS}

Atherosclerosis is a chronic inflammatory disease that is continuous crosstalk between the lipid metabolism and immune-inflammatory pathways. Accumulation of intracellular lipids is a fundamental event in atherogenesis at the cellular level. The accumulation of intracellular modified lipids, especially ox-LDL, leads to foam cell formation. Inflammation participates in all phases of atherosclerosis. Lipid droplets accumulate in the cytoplasm of Pericytes, macrophages, and smooth muscle cells and lead to change their appearance. All risk factors of atherosclerosis cause an inflammatory response. Inflammatory cytokines cause the accumulation of intracellular lipids. Intracellular lipids accumulation leads to rupture of the cells. As a result of the increase of proinflammatory cytokines, endoplasmic reticulum stress in the arterial wall cells and apoptosis occur. This process and cytokineinduced inflammation lead to interrupt the normal activity of

\section{REFERENCES}

1. Ruparelia N, Chai JT, Fisher EA, Choudhury RP. Inflammatory processes in cardiovascular disease: a route to targeted therapies. Nat Rev Cardiol. (2017) 14:133-44. doi: 10.1038/nrcardio.2016.185

2. Orekhov AN, Ivanova EA. Introduction of the special issue "atherosclerosis and related diseases". Vessel Plus. (2017) 1:163-5. doi: 10.20517/2574-1209.2017.33

3. Malekmohammad K, Sewell RD, Rafieian-Kopaei M. Antioxidants and atherosclerosis: mechanistic aspects. Biomolecules. (2019) 9:301. doi: 10.3390/biom 9080301

4. Yan $\mathrm{Y}$, Song $\mathrm{D}$, Wu J, Wang J. Long non-coding RNAs link oxidized low-density lipoprotein with the inflammatory response of macrophages in atherogenesis. Front Immunol. (2020) 11:1-11. doi: 10.3389/fimmu.2020.00024 mitochondria and then impaired mitophagy and apoptosis. Thus, both lipoprotein metabolism and inflammatory immune response play vital roles in the initiation, perpetuation, and eventually, resolution of the atherosclerosis process.

This information leads to the development of new approaches to the diagnosis and treatment of atherosclerosis such as evaluation of microRNAs and lncRNAs. On the other hand, new developments based on using cell models, medicinal plants, and natural products as therapeutic tools have been developed to prevent lipid accumulation and foam cell formation. Recently, lncRNAs and miRNAs have been considered for the treatment and prevention of atherosclerosis. Hence, the therapeutic effects of these molecules, especially lncRNAs, have largely remained experimental at this time. Expressing the therapeutic effect of these molecules with more details and their mechanism of action needs more experiments and research in the future. Totally, various lncRNAs and miRNAs can prevent and treat atherosclerosis by regulating HDL biogenesis, cholesterol efflux, lipid metabolism, regulating smooth muscle proliferation, and controlling inflammation.

Medicinal plants and their active compounds can prevent atherosclerosis through the following mechanisms: in fact, medicinal plants decrease total cholesterol, LDL-C, and TG. Various bioactive compounds reduce LOX-1 expression. They inhibit ROS production. Natural products inhibit the foam cell formation and SR-B1 expression. Also, the production of IL-1 $\beta$, TNF- $\alpha$, INF- $\gamma$, MCP-1, and ICAM-1 is inhibited by different medicinal plants.

\section{AUTHOR CONTRIBUTIONS}

KM and MR-K: conceptualization. MR-K: methodology and supervision. KM, EB, and MR-K: writing-original draft preparation and writing-review and editing. All authors contributed to the article and approved the submitted version.

\section{FUNDING}

This research was funded by the Russian Science Foundation, Grant number 18-15-00254.
5. Sies H, Stahl W, Sevanian A. Nutritional, dietary and postprandial oxidative stress. J Nutr. (2005) 135:969-72. doi: 10.1093/jn/135. 5.969

6. Di Pietro N, Formoso G, Pandolfi A. Physiology and pathophysiology of oxLDL uptake by vascular wall cells in atherosclerosis. Vasc Pharmacol. (2016) 84:1-7. doi: 10.1016/j.vph.2016.05.013

7. Nikoforov NG, Gratchev AN, Sobenin IA, Orekhov AN, Kzhyhskowska YG. Interaction of native and modified low density lipoprotein with intimal cells in atherosclerotic lesion. Patol Fiziol Eksp Ter. (2013) 1:109-17.

8. Libby P. Inflammation in atherosclerosis. Nature. (2002) 420:86874. doi: $10.1038 /$ nature 01323

9. Boamponsem AG, Boamponsem LK. The role of inflammation in atherosclerosis. Adv Appl Sci Res. (2011) 2:194-207.

10. Libby P. Inflammation in atherosclerosis. Arter Thromb Vasc Biol. (2012) 32:2045-51. doi: 10.1161/ATVBAHA.108.179705 
11. Lind L. Circulating markers of inflammation and atherosclerosis. Atherosclerosis. (2003) 169:203-14. doi: 10.1016/S0021-9150(03)00012-1

12. Patel S, Celermajer DS, Bao S. Atherosclerosis-Underlying inflammatory mechanisms and clinical implications. Int J Biochem Cell Biol. (2008) 40:57680. doi: 10.1016/j.biocel.2007.11.017

13. Ouweneel AB, Van Eck M. Lipoproteins as modulators of atherothrombosis: from endothelial function to primary and secondary coagulation. Vasc Pharmacol. (2016) 82:1-10. doi: 10.1016/j.vph.2015.10.009

14. Wang T, Butany J. Pathogenesis of atherosclerosis. Diagn Histopathol. (2017) 23:473-8. doi: 10.1016/j.mpdhp.2017.11.009

15. Buckley ML, Ramji DP. The influence of dysfunctional signaling and lipid homeostasis in mediating the inflammatory responses during atherosclerosis. Biochim Biophys Acta Mol Basis Dis. (2015) 1852:1498510. doi: 10.1016/j.bbadis.2015.04.011

16. Bäck M, Yurdagul A, Tabas I, Öörni K, Kovanen PT. Inflammation and its resolution in atherosclerosis: mediators and therapeutic opportunities. Nat Rev Cardiol. (2019) 16:389-406. doi: 10.1038/s41569-019-0169-2

17. Wolf D, Ley K. Immunity and inflammation in atherosclerosis. Circ Res. (2019) 124:315-27. doi: 10.1161/CIRCRESAHA.118.313591

18. Kinscherf R, Claus R, Deigner HP, Nauen O, Gehrke C, Hermetter A, et al. Modified low density lipoprotein delivers substrate for ceramide formation and stimulates the sphingomyelinceramide pathway in human macrophages. FEBS letters. (1997) 405:55-9. doi: 10.1016/S0014-5793(97)00157-9

19. Mukhin DN, Chao FF, Kruth HS. Glycosphingolipid accumulation in the aortic wall is another feature of human atherosclerosis. Arterioscler Thromb Vasc Biol. (1995) 15:1607-15. doi: 10.1161/01.ATV.15.10.1607

20. Chatterjee SB, Dey S, Shi WY, Thomas K, Hutchins GM. Accumulation of glycosphingolipids in human atherosclerotic plaque and unaffected aorta tissues. Glycobiology. (1997) 7:57-65. doi: 10.1093/glycob/7.1.57

21. Spagnoli LG, Bonanno E, Sangiorgi G, Mauriello A. Role of inflammation in atherosclerosis. J. Nucl Med. (2007) 48:180015. doi: 10.2967/jnumed.107.038661

22. Chistiakov DA, Melnichenko AA, Myasoedova VA, Grechko AV, Orekhov AN. Mechanisms of foam cell formation in atherosclerosis. J Mol Med. (2017) 95:1153-65. doi: 10.1007/s00109-017-1575-8

23. Bories GF, Leitinger N. Macrophage metabolism in atherosclerosis. FEBS Lett. (2017) 591:3042-60. doi: 10.1002/1873-3468.12786

24. Summerhill VI, Grechko AV, Yet SF, Sobenin IA, Orekhov AN. The atherogenic role of circulating modified lipids in atherosclerosis. Int J Mol Sci. (2019) 20:3561. doi: 10.3390/ijms20143561

25. Borén J, Williams KJ. The central role of arterial retention of cholesterolrich apolipoprotein-B-containing lipoproteins in the pathogenesis of atherosclerosis: a triumph of simplicity. Curr Opin Lipidol. (2016) 27:47383. doi: 10.1097/MOL.0000000000000330

26. Meiliana A, Dewi NM, Wijaya A. Advanced in molecular mechanisms of atherosclerosis: from lipids to inflammation. Indones Biomed J. (2018) 10:104-22. doi: 10.18585/inabj.v10i2.479

27. Williams KJ, Tabas I. The response-to-retention hypothesis of early atherogenesis. Arterioscler Thromb Vasc Biol. (1995) 15:551-61. doi: 10.1161/01.ATV.15.5.551

28. Williams KJ, Tabas I. Lipoprotein retention-and clues for atheroma regression. Arterioscler Thromb Vasc Biol. (2005) 25:1536-40. doi: 10.1161/01.ATV.0000174795.62387.d3

29. Nakashima Y, Fujii H, Sumiyoshi S, Wight TN, Sueishi K. Early human atherosclerosis: accumulation of lipid and proteoglycans in intimal thickenings followed by macrophage infiltration. Arterioscler Thromb Vasc Biol. (2007) 27:1159-65. doi: 10.1161/ATVBAHA.106. 134080

30. Poznyak AV, Wu WK, Melnichenko AA, Wetzker R, Sukhorukov $\mathrm{V}$, Markin AM, et al. Signaling pathways and key genes involved in regulation of foam cell formation in atherosclerosis. Cells. (2020) 9:584. doi: 10.3390/cells9030584

31. Miller YI, Choi SH, Fang L, Tsimikas S. Lipoprotein modification and macrophage uptake: role of pathologic cholesterol transport in atherogenesis. Subcell Biochem. (2010) 51:229-51. doi: 10.1007/978-90-4818622-8_8
32. Sukhorukov VN, Khotina VA, Chegodaev YS, Ivanova E, Sobenin IA, Orekhov AN. Lipid metabolism in macrophages: focus on atherosclerosis. Biomedicines. (2020) 8:262. doi: 10.3390/biomedicines 8080262

33. Hirayama S, Miida T. Small dense LDL: an emerging risk factor for cardiovascular disease. Clinica Chimica Acta. (2012) 414:215-24. doi: 10.1016/j.cca.2012.09.010

34. Orekhov AN, Myasoedova VA. Low density lipoprotein-induced lipid accumulation is a key phenomenon of atherogenesis at the arterial cell level. Vessel Plus. (2019) 3:3. doi: 10.20517/2574-1209.2018.80

35. Lehti S, Nguyen SD, Belevich I, Vihinen H, Heikkilä HM, Soliymani R, et al. Extracellular lipids accumulate in human carotid arteries as distinct threedimensional structures and have proinflammatory properties. Am J Pathol. (2018) 188:525-38. doi: 10.1016/j.ajpath.2017.09.019

36. Guarino AJ, Tulenko TN, Wrenn SP. Cholesterol crystal nucleation from enzymatically modified low-density lipoproteins: combined effect of sphingomyelinase and cholesterol esterase. Biochemistry. (2004) 43:168593. doi: $10.1021 / \mathrm{bi} 035747 \mathrm{r}$

37. Kelley JL, Ozment TR, Li C, Schweitzer JB, Williams DL. Scavenger receptorA (CD204): a two-edged sword in health and disease. Crit Rev Immunol. (2014) 34:241-61. doi: 10.1615/CritRevImmunol.2014010267

38. Benitez-Amaro A, Pallara C, Nasarre L, Rivas-Urbina A, Benitez S, Vea A, et al. Molecular basis for the protective effects of lowdensity lipoprotein receptor-related protein 1 (LRP1)-derived peptides against LDL aggregation. Biochim Biophys Acta. (2019) 1861:130216. doi: 10.1016/j.bbamem.2019.05.003

39. Orekhov AN, Nikiforov NG, Sukhorukov VN, Kubekina MV, Sobenin IA, $\mathrm{Wu} \mathrm{WK}$, et al. Role of phagocytosis in the pro-inflammatory response in LDL-induced foam cell formation; a transcriptome analysis. Int J Mol Sci. (2020) 21:817. doi: 10.3390/ijms21030817

40. Singh RK, Haka AS, Asmal A, Barbosa-Lorenzi VC, Grosheva I, Chin HF, et al. TLR4 (Toll-Like Receptor 4)-dependent signaling drives extracellular catabolism of LDL (Low-Density Lipoprotein) aggregates. Arterioscler Thromb Vasc Biol. (2020) 40:86-102. doi: 10.1161/ATVBAHA.119.313200

41. Nigorikawa K, Matsumura T, Sakamoto H, Morioka S, Kofuji S, Takasuga S, et al. Sac1 phosphoinositide phosphatase regulates foam cell formation by modulating SR-A expression in macrophages. Biol Pharm Bull. (2019) 42:923-8. doi: 10.1248/bpb.b18-00907

42. Hashizume M, Mihara M. Atherogenic effects of TNF- $\alpha$ and IL6 via up-regulation of scavenger receptors. Cytokine. (2012) 58:42430. doi: 10.1016/j.cyto.2012.02.010

43. Zhao L, Varghese Z, Moorhead JF, Chen Y, Ruan XZ. CD36 and lipid metabolism in the evolution of atherosclerosis. Br Med Bull. (2018) 126:10112. doi: $10.1093 / \mathrm{bmb} / \mathrm{ldy} 006$

44. Park YM. CD36, a scavenger receptor implicated in atherosclerosis. Exp Mol Med. (2014) 46:e99. doi: 10.1038/emm.2014.38

45. Calabresi L, Gomaraschi M, Simonelli S, Bernini F, Franceschini G. HDL and atherosclerosis: insights from inherited HDL disorders. Biochim Biophys Acta. (2015) 1851:13-8. doi: 10.1016/j.bbalip.2014.07.015

46. De Nardo D, Labzin LI, Kono H, Seki R, Schmidt SV, Beyer M, et al. High-density lipoprotein mediates anti-inflammatory reprogramming of macrophages via the transcriptional regulator ATF3. Nat Immunol. (2014) 15:152-60. doi: $10.1038 /$ ni.2784

47. Niyonzima N, Samstad EO, Aune MH, Ryan L, Bakke SS, Rokstad AM, et al. Reconstituted high-density lipoprotein attenuates cholesterol crystalinduced inflammatory responses by reducing complement activation. $J$ Immunol. (2015) 195:257-64. doi: 10.4049/jimmunol.1403044

48. Bursill CA, Castro ML, Beattie DT, Nakhla S, Van Der Vorst E, Heather AK, et al. High-density lipoproteins suppress chemokines and chemokine receptors in vitro and in vivo. Arterioscler Thromb Vasc Biol. (2010) 30:17738. doi: 10.1161/ATVBAHA.110.211342

49. Moore KJ, Fisher EA. High-density lipoproteins put out the fire. Cell Metab. (2014) 19:175. doi: 10.1016/j.cmet.2014.01.009

50. Osler W. Diseases of the arteries. In: Osler W, editor. Modern Medicine: Its Practice and Theory. Philadelphia, PA: Lea and Febiger (1908). p. 429-47.

51. Ridker PM, Howard CP, Walter V, Everett B, Libby P, Hensen J, et al. Effects of interleukin- $1 \beta$ inhibition with canakinumab on hemoglobin A1c, lipids, C-reactive protein, interleukin-6, and fibrinogen: a phase 
IIb randomized, placebo-controlled trial. Circulation. (2012) 126:273948. doi: 10.1161/CIRCULATIONAHA.112.122556

52. Mofidi R, Crotty TB, McCarthy P, Sheehan SJ, Mehigan D, Keaveny TV. Association between plaque instability, angiogenesis and symptomatic carotid occlusive disease. Br J Surg. (2001) 88:945-50. doi: 10.1046/j.0007-1323.2001.01823.x

53. Kaperonis EA, Liapis CD, Kakisis JD, Dimitroulis D, Papavassiliou VG. Inflammation and atherosclerosis. Eur J. Vasc Endovasc Surg. (2006) 31:38693. doi: 10.1016/j.ejvs.2005.11.001

54. Silva GM, França-Falcão MS, Calzerra NTM, Luz MS, Gadelha DDA, Balarini CM, et al. Role of renin-angiotensin system components in atherosclerosis: focus on Ang-II, ACE2, and Ang-1-7. Front Physiol. (2020) 11:1067-74. doi: 10.3389/fphys.2020.01067

55. Poznyak A, Grechko AV, Poggio P, Myasoedova VA, Alfieri V, Orekhov AN. The diabetes mellitus-atherosclerosis connection: the role of lipid and glucose metabolism and chronic inflammation. Int J Mol Sci. (2020) 21:1835-48. doi: 10.3390/ijms21051835

56. La Sala L, Prattichizzo F, Ceriello A. The link between diabetes and atherosclerosis. Eur J Prev. Cardiol. (2019) 26:15-24. doi: 10.1177/2047487319878373

57. Battineni G, Sagaro GG, Chintalapudi N, Amenta F, Tomassoni D, Tayebati SK. Impact of obesity-induced inflammation on cardiovascular diseases (CVD). Int J Mol Sci. (2021) 22:4798-816. doi: 10.3390/ijms22094798

58. Yoo HJ, Choi KM. Adipokines as a novel link between obesity and atherosclerosis. World J Diabetes. (2014) 5:35763. doi: $10.4239 /$ wjd.v5.i3.357

59. Medina-Leyte DJ, Zepeda-García O, Domínguez-Pérez M, GonzálezGarrido A, Villarreal-Molina T, Jacobo-Albavera L. Endothelial dysfunction, inflammation and coronary artery disease: potential biomarkers and promising therapeutical approaches. Int J Mol Sci. (2021) 22:385078. doi: $10.3390 /$ ijms 22083850

60. Reinders ME, Sho M, Robertson SW, Geehan CS, Briscoe DM. Proangiogenic function of CD40 ligand-CD40 interactions. J Immunol. (2003) 171:153441. doi: 10.4049/jimmunol.171.3.1534

61. Melter M, Reinders ME, Sho M, Pal S, Geehan C, Denton MD, et al. Ligation of CD40 induces the expression of vascular endothelial growth factor by endothelial cells and monocytes and promotes angiogenesis in vivo. Blood. (2000) 96:3801-8. doi: 10.1182/blood.V96.12.3801

62. Urbich C, Dernbach E, Aicher A, Zeiher AM, Dimmeler S. CD40 ligand inhibits endothelial cell migration by increasing production of endothelial reactive oxygen species. Circulation. (2002) 106:9816. doi: 10.1161/01.CIR.0000027107.54614.1A

63. Mallat Z, Corbaz A, Scoazec A, Besnard S, Lesèche G, Chvatchko $\mathrm{Y}$, et al. Expression of interleukin-18 in human atherosclerotic plaques and relation to plaque instability. Circulation. (2001) 104:1598-603. doi: 10.1161/hc3901.096721

64. Akhmedov A, Sawamura T, Chen CH, Kraler S, Vdovenko D, Lüscher TF. Lectin-like oxidized low-density lipoprotein receptor-1 (LOX-1): a crucial driver of atherosclerotic cardiovascular disease. Eur Heart J. (2021) 42:1797807. doi: 10.1093/eurheartj/ehaa770

65. Galkina E, Ley K. Immune and inflammatory mechanisms of atherosclerosis. Annu Rev Immunol. (2009) 27:16597. doi: 10.1146/annurev.immunol.021908.132620

66. Orekhov AN, Bobryshev YV, Chistiakov DA. The complexity of cell composition of the intima of large arteries: focus on pericyte-like cells. Cardiovasc Res. (2014) 103:438-51. doi: 10.1093/cvr/cvul68

67. Ivanova EA, Orekhov AN. Cellular model of atherogenesis based on pluripotent vascular wall pericytes. Stem Cells Int. (2016) 2016:7321404. doi: 10.1155/2016/732 1404

68. Markin AM, Sobenin IA, Grechko AV, Zhang D, Orekhov AN. Cellular mechanisms of human atherogenesis: focus on chronification of inflammation and mitochondrial mutations. Front Pharmacol. (2020) 11:642-52. doi: 10.3389/fphar.2020.00642

69. Orekhov AN, Ivanova EA. Cellular models of atherosclerosis and their implication for testing natural substances with anti-atherosclerotic potential. Phytomedicine. (2016) 23:1190-7. doi: 10.1016/j.phymed.2016. 01.003
70. Ivanova EA, Orekhov AN. The role of endoplasmic reticulum stress and unfolded protein response in atherosclerosis. Int J Mol Sci. (2016) 17:193204. doi: 10.3390/ijms 17020193

71. Gkikas I, Palikaras K, Tavernarakis N. The role of mitophagy in innate immunity. Front Immunol. (2018) 9:128398. doi: 10.3389/fimmu.2018.01283

72. Orekhov AN, Zhelankin AV, Kolmychkova KI, Mitrofanov K, Kubekina MV, Ivanova EA. Susceptibility of monocytes to activation correlates with atherogenic mitochondrial DNA mutations. Exp Mol Pathol. (2015) 99:6726. doi: 10.1016/j.yexmp.2015.11.006

73. Orekhov AN, Poznyak AV, Sobenin IA, Nikifirov NN, Ivanova EA. Mitochondrion as a selective target for treatment of atherosclerosis: role of mitochondrial DNA mutations and defective mitophagy in the pathogenesis of atherosclerosis and chronic inflammation. Curr Neuropharmacol. (2020) 18:1064-75. doi: 10.2174/1570159X17666191118125018

74. Orekhov AN, Nikiforov NG, Ivanova EA, Sobenin IA. Possible role of mitochondrial DNA mutations in chronification of inflammation: focus on atherosclerosis. J Clin Med. (2020) 9:E978. doi: 10.3390/jcm9040978

75. Gibson MS, Domingues N, Vieira OV. Lipid and non-lipid factors affecting macrophage dysfunction and inflammation in atherosclerosis. Front Physiol. (2018) 9:654-72. doi: 10.3389/fphys.2018.00654

76. Murray RZ, Stow JL. Cytokine secretion in macrophages: SNAREs, rabs, and membrane trafficking. Front Immunol. (2014) 5:538-47. doi: 10.3389/fimmu.2014.00538

77. Pierce JB, Feinberg MW. Long noncoding RNAs in atherosclerosis and vascular injury: pathobiology, biomarkers, and targets for therapy. Arterioscler Thromb Vasc Biol. (2020) 40:200217. doi: 10.1161/ATVBAHA. 120.314222

78. Li H, Zhu H, Ge J. Long noncoding RNA: recent updates in atherosclerosis. Int J Biol Sci. (2016) 12:898. doi: 10.7150/ijbs.14430

79. Shi X, Wei YT, Li H, Jiang T, Zheng XL, Yin $\mathrm{K}$, et al. Long noncoding RNA H19 in atherosclerosis: what role? Mol Med. (2020) 26:112. doi: 10.1186/s10020-020-00196-w

80. Lee KH, Hwang HJ, Cho JY. Long non-coding RNA associated with cholesterol homeostasis and its involvement in metabolic diseases. Int $\mathrm{J} \mathrm{Mol}$ Sci. (2020) 21:8337. doi: 10.3390/ijms21218337

81. Zhang L, Cheng H, Yue Y, Li S, Zhang D, He R. TUG1 knockdown ameliorates atherosclerosis via up-regulating the expression of miR-133a target gene FGF1. Cardiovasc Pathol. (2018) 33:6-15. doi: 10.1016/j.carpath.2017.11.004

82. Han Y, Ma J, Wang J, Wang L. Silencing of H19 inhibits the adipogenesis and inflammation response in ox-LDL-treated Raw264 7 cells by up-regulating miR-130b. Mol Immunol. (2018) 93:10714. doi: 10.1016/j.molimm.2017.11.017

83. Hofmann P, Sommer J, Theodorou K, Kirchhof L, Fischer A, Li Y, et al. Long non-coding RNA H19 regulates endothelial cell aging via inhibition of STAT3 signalling. Cardiovasc Res. (2019) 115:23042. doi: $10.1093 / \mathrm{cvr} / \mathrm{cvy} 206$

84. Hu Y, Li S, Zou Y. Knockdown of LncRNA H19 relieves LPS-induced damage by modulating miR-130a in osteoarthritis. Yonsei Med J. (2019) 60:381. doi: 10.3349/ymj.2019.60.4.381

85. Hu YW, Zhao JY, Li SF, Huang JL, Qiu YR, Ma X, et al. RP5833A20 1/miR-382-5p/NFIA-dependent signal transduction pathway contributes to the regulation of cholesterol homeostasis and inflammatory reaction. Arterioscler Thromb Vasc Biol. (2015) 35:87-101. doi: 10.1161/ATVBAHA.114.304296

86. Shen S, Zheng X, Zhu Z, Zhao S, Zhou Q, Song Z, et al. Silencing of GAS5 represses the malignant progression of atherosclerosis through upregulation of miR-135a. Biomed Pharmacother. (2019) 118:109302. doi: 10.1016/j.biopha.2019.109302

87. Ye J, Wang C, Wang D, Yuan H. LncRBA GSA5, up-regulated by oxLDL, aggravates inflammatory response and MMP expression in THP-1 macrophages by acting like a sponge for miR-221. Exp Cell Res. (2018) 369:348-55. doi: 10.1016/j.yexcr.2018.05.039

88. Bochenek G, Häsler R, El Mokhtari NE, König IR, Loos BG, Jepsen S, et al. The large non-coding RNA ANRIL, which is associated with atherosclerosis, periodontitis and several forms of cancer, regulates ADIPOR1, VAMP3 and C11ORF10. Hum Mol Genet. (2013) 22:4516-27. doi: 10.1093/hmg/ddt299 
89. Zhou X, Han X, Wittfeldt A, Sun J, Liu C, Wang X, et al. Long non-coding RNA ANRIL regulates inflammatory responses as a novel component of NF-kB pathway. RNA Biol. (2016) 13:98-108. doi: 10.1080/15476286.2015.1122164

90. Liu Y, Jia L, Min D, Xu Y, Zhu J, Sun Z. Baicalin inhibits proliferation and promotes apoptosis of vascular smooth muscle cells by regulating the MEG3/p53 pathway following treatment with ox-LDL. Int J Mol Med. (2019) 43:901-13. doi: 10.3892/ijmm.2018.4009

91. Wang M, Li C, Zhang Y, Zhou X, Liu Y, Lu C. LncRNA MEG3-derived miR361-5p regulate vascular smooth muscle cells proliferation and apoptosis by targeting ABCA1. Am J Transl Res. (2019) 11:3600.

92. Zhang Y, Liu X, Bai X, Lin Y, Li Z, Fu J, et al. Melatonin prevents endothelial cell pyroptosis via regulation of long noncoding RNA MEG3/miR223/NLRP3 axis. J Pineal Res. (2018) 64:e12449. doi: 10.1111/jpi.12449

93. Zhaolin Z, Guohua L, Shiyuan W, Zuo W. Role of pyroptosis in cardiovascular disease. Cell Prolif. (2019) 52:e12563. doi: 10.1111/cpr.12563

94. Zhen Z, Ren S, Ji H, Ding X, Zou P, Lu J. The lncRNA DAPK-IT1 regulates cholesterol metabolism and inflammatory response in macrophages and promotes atherogenesis. Biochem Biophys Res Commun. (2019) 516:123441. doi: 10.1016/j.bbrc.2019.06.113

95. Li H, Zhao Q, Chang L, Wei C, Bei H, Yin Y, et al. LncRNA MALAT1 modulates ox-LDL induced EndMT through the Wnt/b-catenin signaling pathway. Lipids Health Dis. (2019) 18:62-72. doi: 10.1186/s12944-019-1006-7

96. Wang K, Yang C, Shi J, Gao T. Ox-LDL-induced IncRNA MALAT1 promotes autophagy in human umbilical vein endothelial cells by sponging miR-216a-5p and regulating Beclin-1 expression. Eur J Pharmacol. (2019) 858:172338. doi: 10.1016/j.ejphar.2019.04.019

97. Li S, Pan X, Yang S, Ma A, Yin S, Dong Y, et al. LncRNA MALAT1 promotes oxidized low-density lipoprotein-induced autophagy in HUVECs by inhibiting the PI3K/AKT pathway. J Cell Biochem. (2019) 120:4092101. doi: $10.1002 /$ jcb. 27694

98. Li S, Sun Y, Zhong L, Xiao Z, Yang M, Chen M, et al. The suppression of ox-LDL-induced inflammatory cytokine release and apoptosis of HCAECs by long non-coding RNA-MALAT1 via regulating microRNA155/SOCS1 pathway. Nutr Metab Cardiovasc Dis. (2018) 28:117587. doi: 10.1016/j.numecd.2018.06.017

99. West JA, Davis CP, Sunwoo H, Simon MD, Sadreyev RI, Wang PI, et al. The long noncoding RNAs NEAT1 and MALAT1 bind active chromatin sites. Mol Cell. (2014) 55:791-802. doi: 10.1016/j.molcel.2014.07.012

100. Chen DD, Hui LL, Zhang XC, Chang Q. NEAT1 contributes to ox-LDL-induced inflammation and oxidative stress in macrophages through inhibiting miR-128. J Cell Biochem. (2019) 120:2493-501. doi: 10.1002/jcb.27541

101. Zhong X, Ma X, Zhang L, Li Y, Li Y, He R. MIAT promotes proliferation and hinders apoptosis by modulating miR-181b/STAT3 axis in oxLDLinduced atherosclerosis cell models. Biomed Pharmacother. (2018) 97:1078-85. doi: 10.1016/j.biopha.2017.11.052

102. Wang R, Zhang Y, Xu L, Lin Y, Yang X, Bai L, et al. Protein inhibitor of activated STAT3 suppresses oxidized LDL-induced cell responses during atherosclerosis in apolipoprotein E-deficient mice. Sci Rep. (2016) 6:13. doi: $10.1038 /$ srep36790

103. Li Y, Sun T, Shen S, Wang L, Yan J. LncRNA DYNLRB2-2 inhibits THP-1 macrophage foam cell formation by enhancing autophagy. Biol Chem. (2019) 400:1047-57. doi: 10.1515/hsz-2018-0461

104. Li Y, Shen S, Ding S, Wang L. LincRNA DYN-LRB2-2 upregulates cholesterol efflux by decreasing TLR2 expression in macrophages. J Cell Biochem. (2018) 119:1911-21. doi: 10.1002/jcb.26352

105. Hu YW, Yang JY, Ma X, Chen ZP, Hu YR, Zhao JY, et al. A lincRNADYNLRB2-2/GPR119/GLP-1R/ABCA1-dependent signal transduction pathway is essential for the regulation of cholesterol homeostasis. J Lipid Res. (2014) 55:681-97 doi: 10.1194/jlr.M044669

106. Li H, Han S, Sun Q, Yao Y, Li S, Yuan C, et al. Long non-coding RNA CDKN2B-AS1 reduces inflammatory response and promotes cholesterol efflux in atherosclerosis by inhibiting ADAM10 expression. Aging. (2019) 11:1695. doi: 10.18632/aging.101863

107. Javadifar A, Rastgoo S, Banach M, Jamialahmadi T, Johnston TP, Sahebkar A. Foam cells as therapeutic targets in atherosclerosis with a focus on the regulatory roles of non-coding RNAs. Int J Mol Sci. (2021) 22:252956. doi: 10.3390/ijms22052529

108. Chen KC, Juo SHH. MicroRNAs in atherosclerosis. Kaohsiung J Med Sci. (2012) 28:631-40. doi: 10.1016/j.kjms.2012.04.001

109. Meiliana A, Wijaya A. MicroRNAs in lipid metabolism and atherosclerosis. Indones Biomed J. (2014) 6:3-16. doi: 10.18585/inabj.v6i1.39

110. $\mathrm{Lu} \mathrm{Y,} \mathrm{Thavarajah} \mathrm{T}, \mathrm{Gu} \mathrm{W}$, Cai J, Xu Q. Impact of miRNA in atherosclerosis. Arterioscler Thromb Vasc Biol. (2018) 38:e159-70. doi: 10.1161/ATVBAHA.118.310227

111. Li X, Kong D, Chen H, Liu S, Hu H, Wu T, et al. miR-155 acts as an anti-inflammatory factor in atherosclerosis-associated foam cell formation by repressing calcium-regulated heat stable protein 1. Sci Rep. (2016) 6:111. doi: $10.1038 /$ srep2 1789

112. Zhu J, Chen T, Yang L, Li Z, Wong MM, Zheng X, et al. Regulation of microRNA-155 in atherosclerotic inflammatory responses by targeting MAP3K10. PLoS ONE. (2012) 7:e46551. doi: 10.1371/journal.pone.004 6551

113. Yang Y, Yang L, Liang X, Zhu G. MicroRNA-155 promotes atherosclerosis inflammation via targeting SOCS1. Cell Physiol Biochem. (2015) 36:137181. doi: 10.1159/000430303

114. Huang RS, Hu GQ, Lin B, Lin ZY, Sun CC. MicroRNA-155 silencing enhances inflammatory response and lipid uptake in oxidized low-density lipoprotein-stimulated human THP-1 macrophages. J Investig Med. (2010) 58:961-7. doi: 10.2310/JIM.0b013e3181ff46d7

115. Chen T, Huang Z, Wang L, Wang Y, Wu F, Meng S, et al. MicroRNA125a-5p partly regulates the inflammatory response, lipid uptake, and ORP9 expression in oxLDL-stimulated monocyte/macrophages. Cardiovasc Res. (2009) 83:131-9. doi: 10.1093/cvr/cvp121

116. Yang K, He YS, Wang XQ, Lu L, Chen QJ, Liu J, et al. MiR-146a inhibits oxidized low-density lipoprotein-induced lipid accumulation and inflammatory response via targeting toll-like receptor 4. FEBS Letters. (2011) 585:854-60. doi: 10.1016/j.febslet.2011.02.009

117. Chen T, Li Z, Zhu W, Ge J, Zheng X, Pan X, et al. MicroRNA-146a regulates the maturation process and pro-inflammatory cytokine secretion by targeting CD40L in oxLDL-stimulated dendritic cells. FEBS Letters. (2011) 585:567-73. doi: 10.1016/j.febslet.2011.01.010

118. Taganov KD, Boldin MP, Chang KJ, Baltimore D. NF-kappaB-dependent induction of microRNA miR-146, an inhibitor targeted to signaling proteins of innate immune responses. Proc Natl Acad Sci USA. (2006) 103:124816. doi: 10.1073/pnas.0605298103

119. Gerin I, Clerbaux LA, Haumont O, Lanthier N, Das AK, Burant CF, et al. Expression of miR-33 from an SREBP2 intron inhibits cholesterol export and fatty acid oxidation. J Biol Chem. (2010) 285:3365261. doi: 10.1074/jbc.M110.152090

120. Marquart TJ, Allen RM, Ory DS, Baldán Á. miR-33 links SREBP-2 induction to repression of sterol transporters. Proc Natl Acad Sci. (2010) 107:1222832. doi: 10.1073/pnas.1005191107

121. Zhao T, Li J, Chen AF. MicroRNA-34a induces endothelial progenitor cell senescence and impedes its angiogenesis via suppressing silent information regulator 1. Am J Physiol Endocrinol Metab. (2010) 299:E110 E6. doi: 10.1152/ajpendo.00192.2010

122. Fang Y, Shi C, Manduchi E, Civelek M, Davies PF. MicroRNA10 a regulation of proinflammatory phenotype in athero-susceptible endothelium in vivo and in vitro. Proc Natl Acad Sci. (2010) 107:13450 5. doi: 10.1073/pnas.1002120107

123. Staszel T, Zapała B, Polus A, Sadakierska-Chudy A, Kieć-Wilk B, Stepień $\mathrm{E}$, et al. Role of microRNAs in endothelial cell pathophysiology. Pol Arch Med Wewn. (2011) 121:361-7 doi: 10.20452/pamw. 1093

124. Kumar S, Kim CW, Simmons RD, Jo H. Role of flow-sensitive microRNAs in endothelial dysfunction and atherosclerosis: mechanosensitive athero-miRs. Arterioscler Thromb Vasc Biol. (2014) 34:2206-16. doi: 10.1161/ATVBAHA.114.303425

125. Neth P, Nazari-Jahantigh M, Schober A, Weber C. MicroRNAs in flow-dependent vascular remodelling Cardiovasc Res. (2013) 99:294303. doi: $10.1093 /$ cvr/cvt096

126. Huang $\mathrm{X}$, Yue $\mathrm{Z}$, Wu J, Chen J, Wang S, Wu J, et al. MicroRNA21 knockout exacerbates angiotensin ii-induced thoracic aortic aneurysm 
and dissection in mice with abnormal transforming growth factor$\beta$-SMAD3 signaling. Arterioscler Thromb Vasc Biol. (2018) 38:1086101. doi: 10.1161/ATVBAHA.117.310694

127. Loyer X, Potteaux S, Vion AC, Guérin CL, Boulkroun S, Rautou $\mathrm{PE}$, et al. Inhibition of microRNA-92a prevents endothelial dysfunction and atherosclerosis in mice. Circ Res. (2014) 114:434-43. doi: 10.1161/CIRCRESAHA.114.302213

128. Bauernfeind F, Rieger A, Schildberg FA, Knolle PA, Schmid-Burgk JL, Hornung V. NLRP3 inflammasome activity is negatively controlled by miR223. J Immunol. (2012) 189:4175-81. doi: 10.4049/jimmunol.1201516

129. Weber C, Soehnlein O. ApoE controls the interface linking lipids and inflammation in atherosclerosis. J Clin Investig. (2011) 121:38257. doi: $10.1172 / J C I 60457$

130. Vickers KC, Landstreet SR, Levin MG, Shoucri BM, Toth CL, Taylor RC, et al. MicroRNA-223 coordinates cholesterol homeostasis. Proc Natl Acad Sci. (2014) 111:14518-23. doi: 10.1073/pnas.1215767111

131. Rotllan N, Price N, Pati P, Goedeke L, Fernández-Hernando C. microRNAs in lipoprotein metabolism and cardiometabolic disorders. Atherosclerosis. (2016) 246:352-60. doi: 10.1016/j.atherosclerosis.2016.01.025

132. Wang D, Deuse T, Stubbendorff M, Chernogubova E, Erben RG, Eken SM, et al. Local microRNA modulation using a novel anti-miR-21-eluting stent effectively prevents experimental in-stent restenosis. Arterioscler Thromb Vasc Biol. (2015) 35:1945-53. doi: 10.1161/ATVBAHA.115.305597

133. Kim JY, Shim SH. Medicinal herbs effective against atherosclerosis: classification according to mechanism of action. Biomol Ther. (2019) 27:254. doi: 10.4062/biomolther.2018.231

134. Kirichenko TV, Sukhorukov VN, Markin AM, Nikiforov NG, Liu PY, Sobenin IA, et al. Medicinal plants as a potential and successful treatment option in the context of atherosclerosis. Front Pharmacol. (2020) 11:403. doi: 10.3389/fphar.2020.00403

135. Liu Z, Xu S, Huang X, Wang J, Gao S, Li H, et al. Cryptotanshinone, an orally bioactive herbal compound from Danshen, attenuates atherosclerosis in apolipoprotein E-deficient mice: role of lectin-like oxidized LDL receptor-1 (LOX-1). Br J Pharmacol. (2015) 172:5661-75. doi: 10.1111/bph.13068

136. Ang KP, Tan HK, Selvaraja M, Kadir AA, Somchit MN, Akim $\mathrm{AM}$, et al. Cryptotanshinone attenuates in vitro ox-LDLinduced pre-lesional atherosclerotic events. Planta Med. (2011) 77:1782-7. doi: 10.1055/s-0030-1271119

137. Xu S, Zhong A, Bu X, Ma H, Li W, Xu X, et al. Salvianolic acid B inhibits platelets-mediated inflammatory response in vascular endothelial cells. Thromb Res. (2015) 135:137-45. doi: 10.1016/j.thromres.2014.10.034

138. Cook-Mills JM, Marchese ME, Abdala-Valencia H. Vascular cell adhesion molecule-1 expression and signaling during disease: regulation by reactive oxygen species and antioxidants. Antioxid Redox Signal. (2011) 15:160738. doi: 10.1089 /ars.2010.3522

139. Kwon HM, Choi YJ, Choi JS, Kang SW, Bae JY, Kang IJ, et al. Blockade of cytokine-induced endothelial cell adhesion molecule expression by licorice isoliquiritigenin through NF-kB signal disruption. Exp Biol Med. (2007) 232:235-45. doi: 10.3181/00379727-207-2320235

140. Kang MR, Park KH, Oh SJ, Yun J, Lee CW, Lee MY, et al. Cardiovascular protective effect of glabridin: implications in LDL oxidation and inflammation. Int Immunopharmacol. (2015) 29:914-8. doi: 10.1016/j.intimp.2015.10.020

141. Sendl A, Elbl G, Steinke B, Redl K, Breu W, Wagner H. Comparative pharmacological investigations of Allium ursinum and Allium sativum. Planta Med. (1992) 58:1-7. doi: 10.1055/s-2006-961378

142. Vilahur G, Badimon L. Antiplatelet properties of natural products. Vascul Pharmacol. (2013) 59:67-75. doi: 10.1016/j.vph.2013.08.002

143. Morihara N, Hino A. Aged garlic extract suppresses platelet aggregation by changing the functional property of platelets. J Nat Med. (2017) 71:24956. doi: 10.1007/s11418-016-1055-4

144. Allison GL, Lowe GM, Rahman K. Aged garlic extract inhibits platelet activation by increasing intracellular cAMP and reducing the interaction of GPIIb/IIIa receptor with fibrinogen. Life Sci. (2012) 91:1275-80. doi: 10.1016/j.lfs.2012.09.019

145. Rahman K, Lowe GM, Smith S. Aged garlic extract inhibits human platelet aggregation by altering intracellular signaling and platelet shape change. $J$ Nutr. (2016) 146:410S-5S. doi: 10.3945/jn.114.202408
146. Shen P, Liu MH, Ng TY, Chan YH, Yong EL. Differential effects of isoflavones, from astragalus membranaceus and pueraria thomsonii, on the activation of PPAR $\alpha, \operatorname{PPAR} \gamma$, and adipocyte differentiation in vitro. J Nutr. (2006) 136:899-905. doi: 10.1093/jn/136.4.899

147. Qin H, Liu P, Lin S. Effects of astragaloside IV on the SDF1/CXCR4 expression in atherosclerosis of apoE-/- mice induced by hyperlipaemia. Evid Based Complement Alternat Med. (2015) 2015:1-8. doi: 10.1155/2015/385154

148. Du L, Li J, Zhang X, Wang L, Zhang W. Pomegranate peel polyphenols inhibits inflammation in LPS-induced RAW264. 7 macrophages via the suppression of MAPKs activation. J Funct Foods. (2018) 43:629. doi: 10.1016/j.jff.2018.01.028

149. Mandal A, Bhatia D, Bishayee A. Anti-Inflammatory mechanism involved in pomegranate-mediated prevention of breast cancer: the role of NF-kB and Nrf2 signaling pathways. Nutrients. (2017) 9:436. doi: 10.3390/nu905 0436

150. Harzallah A, Hammami M, Kepczyńska MA, Hislop DC, Arch JR, Cawthorne MA, et al. Comparison of potential preventive effects of pomegranate flower, peel and seed oil on insulin resistance and inflammation in high-fat and high-sucrose diet-induced obesity mice model. Arch Physiol Biochem. (2016) 122:75-87. doi: 10.3109/13813455.2016.1148053

151. Chen SC, Chang YL, Wang DL, Cheng JJ. Herbal remedy magnolol suppresses IL-6-induced STAT3 activation and gene expression in endothelial cells. $\mathrm{Br} J$ Pharmacol. (2006) 148:226-32. doi: 10.1038/sj.bjp.0706647

152. Liu M, Chen X, Ma J, Hassan W, Wu H, Ling J, Shang J. $\beta$-Elemene attenuates atherosclerosis in apolipoprotein E-deficient mice via restoring NO levels and alleviating oxidative stress. Biomed Pharmacother. (2017) 95:1789-98. doi: 10.1016/j.biopha.2017.08.092

153. Gu L, Bai W, Li S, Zhang Y, Han Y, Gu Y, et al. Celastrol prevents atherosclerosis via inhibiting LOX-1 and oxidative stress. PLoS ONE. (2013) 8:e65477. doi: 10.1371/journal.pone.0065477

154. Lin SJ, Yang TH, Chen YH, Chen JW, Kwok CF, Shiao MS, et al. Effects of ginkgo biloba extract on the proliferation of vascular smooth muscle cells in vitro and on intimal thickening and interleukin- $1 \beta$ expression after balloon injury in cholesterol-fed rabbits in vivo. J Cell Biochem. (2002) 85:572-82. doi: $10.1002 /$ jcb.10151

155. Sun DI, Nizamutdinova IT, Kim YM, Cai XF, Lee JJ, Kang SS, et al. Bisacurone inhibits adhesion of inflammatory monocytes or cancer cells to endothelial cells through down-regulation of VCAM-1 expression. Int Immunopharmacol. (2008) 8:1272-81. doi: 10.1016/j.intimp.2008. 05.006

156. Lee YJ, Moon MK, Hwang SM, Yoon JJ, Lee SM, Seo KS, et al. AntiInflammatory effect of buddleja officinalis on vascular inflammation in human umbilical vein endothelial cells. Am J Chin Med. (2010) 38:58598. doi: 10.1142/S0192415X1000807X

157. Tuncer MA, Yaymaci B, Sati L, Cayli S, Acar G, Altug T, et al. Influence of tribulus terrestris extract on lipid profile and endothelial structure in developing atherosclerotic lesions in the aorta of rabbits on a high-cholesterol diet. Acta Histochem. (2009) 111:488-500. doi: 10.1016/j.acthis.2008.06.004

158. Amrani S, Harnafi H, Bouanani NEH, Aziz M, Caid HS, Manfredini S, et al. Hypolipidaemic activity of aqueous ocimum basilicum extract in acute hyperlipidaemia induced by triton WR-1339 in rats and its antioxidant property. Phytother Res. (2006) 20:1040-5. doi: 10.1002/ptr.1961

159. Bao Y, Wang L, Xu Y, Yang Y, Wang L, Si S, et al. Salvianolic acid B inhibits macrophage uptake of modified low density lipoprotein (mLDL) in a scavenger receptor CD36-dependent manner. Atherosclerosis 2012, 223, 152-159. doi: 10.1016/j.atherosclerosis.2012.05.006

160. Zhang Y, Si Y, Yao S, Yang N, Song G, Sang H, et al. Celastrus orbiculatus Thunb. Decreases athero-susceptibility in lipoproteins and the aorta of guinea pigs fed high fat diet. Lipids. (2013) 48:61931. doi: $10.1007 /$ s11745-013-3773-7

161. Wan JB, Lee SM, Wang JD, Wang N, He CW, Wang YT, et al. Panax notoginseng reduces atherosclerotic lesions in ApoE-deficient mice and inhibits TNF-alpha-induced endothelial adhesion molecule expression and monocyte adhesion. J Agric Food Chem. (2009) 57:66927. doi: $10.1021 /$ jf $900529 \mathrm{w}$ 
162. Nader MA, El-Agamy DS, Suddek GM. Protective effects of propolis and thymoquinone on development of atherosclerosis in cholesterolfed rabbits. Arch Pharm Res. (2010) 33:637-43 doi: 10.1007/s12272-0100420-1

163. Young IS, McEneny J. Lipoprotein oxidation and atherosclerosis. Biochem Soc Trans. (2001) 29:358-62. doi: 10.1042/bst0290358

164. Zhao W, Feng H, Guo S, Han Y, Chen X. Danshenol A inhibits TNF- $\alpha$-induced expression of intercellular adhesion molecule-1 (ICAM1) mediated by NOX4 in endothelial cells. Sci Rep. (2017) 7:113. doi: 10.1038/s41598-017-13072-1

165. Sedighi M, Bahmani M, Asgary S, Beyranvand F, Rafieian-Kopaei M. A review of plant-based compounds and medicinal plants effective on atherosclerosis. J Res Med Sci. (2017) 22:30. doi: 10.4103/1735-1995.20 2151

166. Kanda Samy M, Veerendar Channabasappa Y, Bhim Charan M, Tapankumar M. Hepatoprotective and antioxidant role of berberis tinctoria lesch leaves on paracetamol induced hepatic damage in rats. Iran J Pharmacol Ther. (2005) 4:64-69.

167. Lin XL, Liu MH, Hu HJ, Feng HR, Fan XJ, Zou WW, et al. Curcumin enhanced cholesterol efflux by upregulating ABCA1 expression through AMPK-SIRT1-LXRa signaling in THP-1 macrophage-derived foam cells. DNA Cell Biol. (2015) 34:561-72. doi: 10.1089/dna. 2015.2866

168. Zhao JF, Ching LC, Huang YC, Chen CY, Chiang AN, Kou YR, et al. Molecular mechanism of curcumin on the suppression of cholesterol accumulation in macrophage foam cells and atherosclerosis. Mol Nutr Food Res. (2012) 56:691-701. doi: 10.1002/mnfr. 201100735

169. Kocaadam B, Sanlier N. Curcumin, an active component of turmeric (Curcuma longa), and its effects on health. Crit Rev Food Sci Nutr. (2017) 57:2889-95. doi: 10.1080/10408398.2015.1077195

170. Ha AW, Ying T, Kim WK. The effects of black garlic (Allium satvium) extracts on lipid metabolism in rats fed a high fat diet. Nutr Res Pract. (2015) 9:30. doi: 10.4162/nrp.2015.9.1.30

171. Park SH, Paek JH, Shin D, Lee JY, Lim SS, Kang YH. Purple perilla extracts with $\alpha$-asarone enhance cholesterol efflux from oxidized LDL-exposed macrophages. Int J Mol Med. (2015) 35:957-65. doi: 10.3892/ijmm.2015. 2101
172. Nizamutdinova IT, Oh HM, Min YN, Park SH, Lee MJ, Kim JS, et al. Paeonol suppresses intercellular adhesion molecule-1 expression in tumor necrosis factor-alpha-stimulated human umbilical vein endothelial cells by blocking p38, ERK and nuclear factorkappaB signaling pathways. Int Immunopharmacol. (2007) 7:343-50. doi: 10.1016/j.intimp.2006.11.004

173. Hansson GK, Hermansson A. The immune system in atherosclerosis. Nat. Immunol. (2011) 12:204-12. doi: 10.1038/ni.2001

174. Jin UH, Kang SK, Suh SJ, Hong SY, Park SD, Kim DW, et al. Inhibitory effect of salvia miltiorrhia BGE on matrix metalloproteinase-9 activity and migration of TNF- $\alpha$-induced human aortic smooth muscle cells. Vasc Pharmacol. (2006) 44:345-53. doi: 10.1016/j.vph.2006.01.007

175. Suh SJ, Jin UH, Choi HJ, Chang HW, Son JK, Lee SH, et al. Cryptotanshinone from salvia miltiorrhiza BUNGE has an inhibitory effect on TNF- $\alpha$ induced matrix metalloproteinase- 9 production and HASMC migration via down-regulated NF-кB and AP-1. Biochem Pharmacol. (2006) 72:16809. doi: 10.1016/j.bcp.2006.08.013

176. Wang J, Xiong X, Feng B. Cardiovascular effects of salvianolic acid B. Evid Based Complement Alternat Med. (2013) 2013:116. doi: $10.1155 / 2013 / 247948$

Conflict of Interest: The authors declare that the research was conducted in the absence of any commercial or financial relationships that could be construed as a potential conflict of interest.

Publisher's Note: All claims expressed in this article are solely those of the authors and do not necessarily represent those of their affiliated organizations, or those of the publisher, the editors and the reviewers. Any product that may be evaluated in this article, or claim that may be made by its manufacturer, is not guaranteed or endorsed by the publisher.

Copyright (C) 2021 Malekmohammad, Bezsonov and Rafieian-Kopaei. This is an open-access article distributed under the terms of the Creative Commons Attribution License (CC BY). The use, distribution or reproduction in other forums is permitted, provided the original author(s) and the copyright owner(s) are credited and that the original publication in this journal is cited, in accordance with accepted academic practice. No use, distribution or reproduction is permitted which does not comply with these terms. 